NBER WORKING PAPER SERIES

\title{
ACCELERATOR OR BRAKE? CASH FOR CLUNKERS, HOUSEHOLD LIQUIDITY, AND AGGREGATE DEMAND
}

\author{
Daniel Green \\ Brian T. Melzer \\ Jonathan A. Parker \\ Arcenis Rojas \\ Working Paper 22878 \\ http://www.nber.org/papers/w22878 \\ NATIONAL BUREAU OF ECONOMIC RESEARCH \\ 1050 Massachusetts Avenue \\ Cambridge, MA 02138 \\ December 2016, Revised May 2018
}

The content of this article does not reflect the views or policies of the U.S. Bureau of Labor Statistics or the National Bureau of Economic Research. For helpful comments, we thank Meghan Busse, Gabriel Chodorow-Reich, Laura Erhard, seminar participants at the Federal Reserve Bank of Boston, UC Berkeley, Duke, MIT, Rochester, and UT Austin, the Reserve Bank of Australia Quantitative Macroeconomics Workshop, and participants at the 2015 Annual Meetings of the American Economic Association, where this paper was originally presented under its original title: \Accelerator or Brake? Microeconomic estimates of the 'Cash for Clunkers' and Aggregate Demand." We thank Jonathan Cohen for research assistance and Ryan Pfirrmann-Powell for data work on this project from its inception in 2013 to its first draft in 2014.

NBER working papers are circulated for discussion and comment purposes. They have not been peer-reviewed or been subject to the review by the NBER Board of Directors that accompanies official NBER publications.

(C) 2016 by Daniel Green, Brian T. Melzer, Jonathan A. Parker, and Arcenis Rojas. All rights reserved. Short sections of text, not to exceed two paragraphs, may be quoted without explicit permission provided that full credit, including $\odot$ notice, is given to the source. 
Accelerator or Brake? Cash for Clunkers, Household Liquidity, and Aggregate Demand Daniel Green, Brian T. Melzer, Jonathan A. Parker, and Arcenis Rojas

NBER Working Paper No. 22878

December 2016, Revised May 2018

JEL No. D14,E62,G18,H24,H31

\section{ABSTRACT}

We evaluate the Car Allowance Rebate System (CARS) by comparing the vehicle purchases and disposals of households with eligible "clunkers" to those of households with similar, but ineligible, vehicles. We find that CARS caused roughly 500,000 purchases during the program period and that the liquidity provided by CARS was critical for generating this large response. CARS provided less liquidity for households owning clunkers securing loans, since participation required loan repayment. The participation rate of these households was low, which we attribute to liquidity constraints and distinguish from the effects of other indebtedness, household income, and the size of the program subsidy.

\section{Daniel Green \\ Harvard Business School \\ dwgreen@mit.edu}

Brian T. Melzer

Federal Reserve Bank of Chicago

230 S. LaSalle St.

Chicago, IL 60604

bmelzer@frbchi.org
Jonathan A. Parker

MIT Sloan School of Management

100 Main Street, E62-642

Cambridge, MA 02142-1347

and NBER

JAParker@MIT.edu

Arcenis Rojas

U.S. Bureau of Labor Statistics

Postal Square B

2 Massachusetts Avenue, N.E.

Washington, DC 20212-0001

Rojas.Arcenis@BLS.gov 


\section{Introduction}

During the Great Recession, policymakers used a range of fiscal policies to stimulate consumer demand, including temporary tax credits and price subsidies on durable goods. Temporary incentives for the purchase of durable goods, like temporary subsidies for capital investment by businesses, can in theory have large effects by altering the timing of purchases. But the responses to such incentives are often found to be quite low. ${ }^{1} \mathrm{~A}$ possible explanation is that intertemporal substitution is limited by financial constraints. People may forgo substantial price subsidies if they lack the liquidity to make down payments, the debt capacity sufficient to secure loans, or the willingness to increase their leverage.

We study the Car Allowance Rebate System (CARS) program to understand the importance of financial frictions for the impact and design of this type of fiscal stimulus program. Under CARS, colloquially known as "Cash for Clunkers," the U.S. Government provided $\$ 3,500$ to $\$ 4,500$ rebates to consumers who traded in and scrapped old, fuel-inefficient automobiles and purchased new, more efficient ones during July and August of 2009. Transactions were submitted at roughly seven times the anticipated rate, and, despite Congress tripling available funding shortly after the program started, CARS ran out of money in just over a month. Because the rebates were paid at the time of the transaction, rather than as credits on households' tax returns, they could be used as down payments for new vehicles. CARS rebates therefore provided not only a price subsidy, but also the liquidity to exploit it. Separating the liquidity feature of the program from that of the economic subsidy alone, we provide evidence that this aspect of CARS' design-liquidity provision - was critical for the large response to the price subsidy. Further, we estimate the elasticity of new vehicle transactions to the CARS subsidy and so add to the literature quantifying the aggregate effect of the program (e.g., Mian and Sufi (2012) and Hoekstra, Puller, and West (2016)).

We use data from the Consumer Expenditure Interview Survey (CE) and a differences-in-differences approach to measure the causal impact of CARS. Passenger cars rated at 18 miles per gallon (MPG) or lower qualified for the CARS subsidy, while vehicles with efficiency of 19 MPG or higher did not. We use these fuel efficiency cut-offs to create a treatment group of vehicles eligible for CARS ("clunkers") and a control group of similar, but ineligible, vehicles with fuel efficiency ratings above the cut off ("close-toclunkers"). We identify the effect of CARS by comparing the rates at which treatment and control group vehicles are traded in for new vehicles during the program period and thereafter. We exclude from the estimation sample vehicles with fuel efficiency more than 6 MPG above or below the cut off and vehicles with estimated trade-in value above $\$ 5,000$, for which the CARS rebate provided no subsidy. Within the estimation sample the treament and control groups have similar average vehicle value, vehicle age, and owner's income.

We estimate that the CARS program raised the probability that a household with an eligible, lowvalue vehicle exchanged its old vehicle for a new one by one and a half percentage points, which represents roughly a quadrupling of the baseline probability. In dollar terms, CARS raised the average spending on new vehicle purchases by $\$ 320$ for each existing clunker eligible for trade-in under the program, consistent

\footnotetext{
${ }^{1}$ See, for example, Auerbach and Hassett (1992), Caballero, Engel, and Haltiwanger (1997), Desai and Goolsbee (2004), House and Shapiro (2008), Edgerton (2010), Zwick and Mahon (2016). Caballero (1993), Bar-Ilan and Blinder (1992), and Berger and Vavra (2015) study automobile purchase dynamics and Adda and Cooper (2000) studies previous vehicle scrappage subsidies in France.
} 
with our estimate of the increase in the probability of purchase and the average purchase price of about $\$ 22,000$. These results are robust to controlling for vehicle and household characteristics and to conducting the analysis at either the vehicle or the household level. As further validation of our model's identifying assumptions, we confirm that CARS had no effect in two placebo tests. Used vehicle purchases, which were ineligible for CARS, were similar between the treatment and control groups during the program period. New vehicle purchases were likewise similar between the treatment and control groups during the summer of 2008 when no program like CARS was in effect.

Because the CARS program required scrapping the old vehicle, the economic value of the subsidy was the face value of the credit minus the vehicle's trade-in value in the absence of the program. We show that the CARS program increased the probability of purchasing or leasing a new vehicle by half a percentage point per $\$ 1,000$ of economic subsidy. As compared with existing estimates of the average response, our measure of the program impact per dollar of economic subsidy is independent of the distribution of values of existing vehicles (which differ across samples used by previous studies).

The participation in CARS also increased with the liquidity it provided, consistent with some households requiring liquidity to be able to intertemporally substitute and take advantage of the temporary subsidy. For many households, a CARS rebate would have been sufficient to cover a down payment, so that the majority of households could participate in CARS irrespective of their liquid savings. For households that owned old vehicles with outstanding loans, however, the liquidity demands were much higher, as participation required immediate repayment of the prior loan. We find a substantially lower treatment effect of the program for this group of households, consistent with binding liquidity constraints limiting the response to the large price subsidy provided by CARS. In fact, the program had no effect at all on the purchases of households with outstanding loans on their old vehicles. While one might be concerned that households with clunkers that secure loans are less responsive for other reasons, this differential response remains after controlling for differences in the effect of CARS related to household income, liquid assets, and the size of the subsidy. The differential response is also specific to loans secured by the potential trade-in: we find no difference in program response for households with other outstanding loans, presumably because these debts are not due upon participation in CARS.

In contrast to our findings on liquidity constraints, we find no relationship between debt capacity and participation in CARS. Despite apparently low debt capacity, households with income in the bottom tercile (less than $\$ 24,000$ per year after taxes), with high debt payment-to-income ratios (33\% or higher), or with high mortgage leverage (loan-to-value ratio above 100\%) still partake in the CARS program at close to the average rate in the full sample. One potential explanation for this finding is that the CARS rebate provided enough collateral coverage to substantially relax debt capacity constraints. Our statistical power in these subsample tests is low, however, so it may also be that debt capacity had significant effects that we are unable to detect within our sample.

Finally, we estimate the impact of CARS on aggregate vehicle purchases and expenditures. Under the assumption that CARS had no impact on trade-ins of ineligible vehicles, we aggregate the predicted increases in individual purchases across the national distribution of clunkers. We find that CARS caused, in a partialequilibrium sense, 506,000 new purchases, relative to 680,000 vehicles traded in under the program. This 
estimate lies within, but at the upper end of, the range of aggregate impacts found in previous studies. ${ }^{2}$ We further estimate that CARS induced $\$ 11$ billion of new vehicle purchases in the third quarter of 2009 ( $\$ 44$ billion at an annual rate) at a fiscal cost of $\$ 2.85$ billion. While CARS increased consumption demand with minimal government outlays and coincided with the end of the Great Recession, its effect on vehicle spending may have been short-lived. Our analysis does not reject the finding in Mian and Sufi (2012) that demand was drawn from purchases that would have occurred anyway over the subsequent seven months.

Our findings imply that liquidity constraints can substantially reduce the impact of a temporary incentive to purchase durable goods, especially during recessions when financial constraints are the most binding. Therefore, programs that bundle liquidity with subsidies, such as by disbursing rebates at purchase rather than as year-end tax credits or mail-in rebates, maximize take-up and are more equitable across households with varying amounts of liquid savings. ${ }^{3}$ Other constraints on borrowing do not appear to have hindered participation. While we can only measure the impact of CARS as it was implemented in 2009, these implications seem likely to hold more broadly because they held during a financial crisis in which lending standards had tightened significantly.

\section{Related literature}

Our paper relates to the literatures on fiscal stimulus, household financial constraints, and purchases of durable goods. Studies of lump-sum stimulus programs also find an important role for household liquidity in causing spending, but for programs where payments naturally provide liquidity and do not depend on purchase behavior. ${ }^{4}$ Vehicle purchases in particular seem to follow from substantial increases in household liquidity, as caused by cash stimulus payments (Parker, Souleles, Johnson, and McClelland 2013), minimum wage hikes (Aaronson, Agarwal, and French 2012), and tax refunds (Adams, Einav, and Levin 2009). The model in Rampini (2016) highlights the relevance of liquidity constraints for purchase of goods with high durability, such as new vehicles. Around the time of the CARS program, automobile purchases were also sensitive to credit supply (Benmelech, Meisenzahl, and Ramcharan 2016). Finally, the analysis of the Firsttime Homebuyer Tax Credit by Berger, Turner, and Zwick (2016) suggests that take-up was amplified among households for which the credit relaxed down payment constraints (as proxied by FICO score).

With respect to existing research on the CARS program, our paper is unique in using nationallyrepresentative, household-level data as well as the first to measure the roles of household financial constraints and the economic subsidy. Mian and Sufi (2012) compares the rates of new vehicle registrations across cities that differed in their pre-program share of clunkers, and estimates that CARS caused between 340,000 and 400,000 additional purchases by August 2009 but no difference in cumulative purchases by March 2010. We find a larger initial impact, a difference we analyze in Section 6.6. In contrast, we use microdata to study

\footnotetext{
${ }^{2}$ Previous studies by Council of Economic Advisors (2009), National Highway Traffic Safety Administration (2009), Li, Linn, and Spiller (2013), and Mian and Sufi (2012) find that CARS caused between 370,000 and 600,000 purchases in July and August of 2009.

${ }^{3}$ The State Energy Efficient Appliance Rebate Program and the First-Time Homebuyer Tax Credit (FTHBTC), both implemented around the same time as CARS did not provide liquidity, however the FTHBTC was subsequently modified so that the credit could be used toward a down payment.

${ }^{4}$ See Johnson, Parker, and Souleles (2006), Agarwal, Liu, and Souleles (2007), Agarwal and Qian (2014), Broda and Parker (2014), and Di Maggio, Kermani, and Ramcharan (2014).
} 
(and control for) the effect of household characteristics such as liquidity, and to more accurately assign vehicles to similar treatment and comparison groups. That said, our data comprise a relatively small sample of households compared to aggregated data on all households in each geographic area.

Hoekstra, Puller, and West (2016) uses the discontinuity in program eligibility at 18 MPG to identify the effect of CARS on total vehicle spending in Texas. The paper shows that CARS caused owners of just-eligible vehicles to purchase more fuel-efficient, but smaller and substantially less expensive vehicles. Their estimates imply that CARS ultimately reduced aggregate vehicle spending despite inducing an initial increase in spending and purchases at the time of the program. Since the response of owners of 18-MPG vehicles may not be representative of the response of all owners, we measure the average impact of the program using a wider range of fuel efficiencies.

\section{The CARS program}

\subsection{Overview}

The Car Allowance Rebate System (CARS) was designed to stimulate automobile sales and production, and to provide environmental benefits by reducing fuel consumption and pollution. The program provided a $\$ 3,500$ or $\$ 4,500$ credit for trading in an old, fuel-inefficient vehicle and purchasing or leasing a new, more fuel-efficient vehicle. Cars that were traded in were scrapped by having the engine and drivetrain destroyed. Many countries have adopted similar scrappage programs, including Germany, France, the UK, Spain, South Korea, Japan, China, Italy, Portugal and the Netherlands.

In total, CARS provided $\$ 2.85$ billion of credits on nearly 680,000 transactions in July and August of 2009. Congress first considered the program in early 2009 and passed the authorizing legislation on June 24, 2009. The Department of Transportation established program rules one month later, and dealers began submitting transactions on July 27, 2009. Program participation exceeded expectations, with a flow of trade-ins seven times the expected rate (National Highway Traffic Safety Administration 2009), and the initial funding of $\$ 1$ billion was exhausted in the first week. Congress responded by appropriating an additional $\$ 2$ billion that sustained the program through its ultimate end date of August 24, 2009, which was still more than two months ahead of the legal end of the program, November 1, 2009. We measure the impact of the program as implemented, including its early termination.

\subsection{Program eligibility}

In order to receive the CARS credit, a household had to trade in a qualifying vehicle and purchase or lease a new vehicle with sufficient improvement in fuel economy over the trade-in. Whether a trade-in vehicle qualified for the CARS credit also depended on its age, condition, and recent insurance and registration status. For fuel economy, passenger cars and small trucks (category 1 and some category 2 vehicles) qualified if they had a combined (city and highway) fuel economy of 18 miles per gallon or less. Large trucks (category 3 and some category 2 vehicles), for which the Department of Energy does not rate fuel economy, were screened instead on vehicle age, with model-years 2001 and earlier eligible for a credit. Regardless of vehicle type, all trade-ins had to be less than 25 years old (model-year 1984 or later) in order to qualify. Finally, all qualifying 
trade-ins had to be in drivable condition and continuously registered and insured to the current owner for the prior year.

Whether a new purchased or leased vehicle qualified for the CARS credit depended on its price, its fuel economy, and the improvement in fuel economy between the trade-in and the new vehicle. New vehicles were ineligible if the manufacturer suggested retail price exceeded $\$ 45,000$. New passenger automobiles also had to have a combined fuel economy of 22 MPG or higher, and at least 4 MPG greater than the trade-in vehicle. New category 1 trucks were required to have fuel economy of at least $18 \mathrm{MPG}$ and at least $2 \mathrm{MPG}$ greater than the clunker. New category 2 trucks were required to get at least $15 \mathrm{MPG}$ and $1 \mathrm{MPG}$ more than the associated clunker. New category 3 trucks had no minimum MPG but could not be larger than the trade-in vehicle.

\subsection{Program credit and economic subsidy}

The credit on eligible transactions was either $\$ 3,500$ or $\$ 4,500$, with the larger credit granted for greater improvement in fuel economy between the trade-in and the new vehicle. For example, a customer purchasing a new passenger car received a credit of $\$ 3,500$ if the fuel economy improvement was between 4 and 9 MPG and received $\$ 4,500$ if the improvement was $10 \mathrm{MPG}$ or more. Similar rules, but requiring smaller improvements in fuel efficiency, applied to each category of light truck. Table 1 summarizes the credit paid for each combination of new and trade-in vehicle. Credits were remitted directly to dealers, who were responsible for submitting the required documentation.

The economic subsidy provided by the CARS program was not the statutory $\$ 3,500$ or $\$ 4,500$ but instead was this amount less the value of the trade-in. That is, the program did not provide a fixed subsidy that could be received in addition to any private trade-in value. Rather, because trade-ins were scrapped, the CARS program effectively replaced the market value of the used car available outside of the program with the fixed CARS rebate. For example, for a CARS rebate of $\$ 4,500$, the true economic subsidy would be $\$ 0$ for a trade-in with value of $\$ 4,500$, whereas it would be $\$ 3,500$ for a trade-in worth $\$ 1,000$.

Finally, Busse, Knittel, Silva-Risso, and Zettelmeyer (2012) finds no evidence that CARS rebates changed the transaction prices for new vehicles or the subsequent prices of used vehicles eligible for the program. ${ }^{5}$ With the incidence of the program entirely on consumers, there is no need to adjust for price changes in our measure of the economic subsidy.

\section{Data}

\subsection{Data sources}

We use data from four sources. We employ the Bureau of Labor Statistics' (BLS) Consumer Expenditure Survey (CE) for information on car purchases and trade-ins for a stratified random sample of US households.

\footnotetext{
${ }^{5}$ Specifically, the transaction price of new cars (inclusive of manufacturer rebates, trade-in value, and adjusted for options) around the time of CARS is independent of whether a CARS rebate was used in the purchase; changes in manufacturer rebates across vehicles are not related to differences in purchases under CARS; subsequent prices in wholesale used car markets across vehicles were unrelated to the share of vehicles traded in under CARS.
} 
We merge this data with measures of vehicle fuel economy, trade-in values, and vehicle registrations from the Environmental Protection Agency (EPA), Edmunds, and R.L. Polk, respectively.

Our main data come from the CE Interview Survey, which tracks respondents' expenditures for one year through interviews every three months. The survey collects information on the make, model, and modelyear of each household's vehicles when they enter the survey and in each subsequent interview. To preserve respondent confidentiality, the BLS suppresses the vehicle model in the public-use files but, following BLS protocols, we obtained access to confidential internal records that include the vehicle model. The CE provides detailed information on each vehicle acquisition and disposal: the month of the transaction, the purchase or sale price, the type of vehicle (new or used), and whether it was purchased or leased. For purchases, the CE also reports the net purchase price as well as the value of the trade-in, if any. For leases, the CE does not report a "purchase price", but we approximate it with the average manufacturer's suggested retail price for the make, model and model year. If the purchase was financed, the CE reports the amounts of the down payment and the loan. We use this information to measure: 1) the CARS eligibility of potential trade-ins; 2) the sale, trade-in or disposal of an existing vehicle; 3) the purchase or lease of an additional vehicle; 4) and the outstanding debt secured by a potential trade-in. We also use CE information on household demographics, income, assets, and debts.

We measure the fuel economy of CE vehicles using data from the EPA and R.L. Polk. The EPA rates the combined city-highway fuel economy by vehicle make, model, model-year, and the pertinent "model options" such as transmission type and drivetrain. R.L. Polk tracks vehicle registrations for each vehicle type. Since model options are not reported in the CE, we compute each vehicle's weighted average fuel economy, given its make, model, and model-year, weighing each model option by its share of nationwide registrations as of January 2009. We also calculate, for each vehicle, the share of registrations above or below the CARS MPG cutoff. For some records, the CE reports a vehicle that is not in the fuel economy file. For example, a household might report having a 2005 Jeep Cherokee, though Jeep Cherokee was only made through 2004. For such instances, we use the MPG of the same model manufactured one year before or after the reported model-year if it exists. If no match exists within one model-year, we exclude the reported vehicle from our analysis since we cannot reliably estimate the vehicle's eligibility for CARS.

We measure the value of CE vehicles and the associated CARS subsidy using data from Edmunds.com. Edmunds calculates monthly estimates of trade-in value by make, model, and model year from actual transactions reported by car dealers. We use the estimated values in May 2009 for vehicles of average condition.

\subsection{Validating the CE vehicle data: Trade-ins during CARS}

Figure 1 provides validation that the $\mathrm{CE}$ data measure meaningful responses to the CARS program and that consumers are fairly accurate in timing their CARS-related purchases. Panel A shows the share of new vehicle purchases that are associated with vehicle trade-ins of exactly $\$ 3,500$ or $\$ 4,500$, the CARS credit amounts. In most months outside of the program period, very few respondents - roughly $5 \%$ - report tradeins of such amounts. During the CARS program the share increases significantly to $22 \%$ in July 2009 and $39 \%$ in August 2009, the peak month of the program. In contrast, Panel B shows that the corresponding

shares for purchases of used vehicles, which are clearly ineligible for CARS, are low and show no increase around the time of the CARS program. 
Notably, the share of $\$ 3,500$ and $\$ 4,500$ trade-ins for new purchases remains elevated at $23 \%$ in September 2009 after the end of the program. This pattern of delayed program response may reflect the timing of vehicle delivery. An estimated 50,000 CARS transactions entailed September delivery despite the purchase occurring before the program's August 24th end date (Krebs 2009). The timing in the CE is based on household reports of expenditures, and many consumers may have reported the delivery date rather than the purchase date. Another possibility is that the delayed response results from recall error, as households interviewed in the fall of 2009 recall their purchase as occurring in September as opposed to August. Such recall error does not appear to be too severe, however, since the proportion of $\$ 3,500$ and $\$ 4,500$ trade-ins returns to its normal low level by October 2009 .

\section{$5 \quad$ Sample and methodology}

We measure the effect of the CARS program on vehicle purchases by comparing a treatment group of eligible trade-in vehicles to a control group of similar but ineligible vehicles. For this comparison to identify the causal effects of the program, the rates of trade-in and new purchases in the treatment and comparison groups would have to be similar in the absence of the CARS program. Therefore, we construct a relatively homogeneous sample of vehicles, precisely allocate vehicles to treatment and comparison groups based on program eligibility at the vehicle level, and check the similarity of the characteristics of the treatment and control groups.

To construct the sample, we select vehicles owned by CE households as of June 2009. We exclude vehicles manufactured before 1985, since they were ineligible for CARS. We also exclude vehicles with average tradein values above $\$ 5,000$, for which the CARS rebate likely provided no economic subsidy. Finally, we exclude vehicles of extreme fuel economy, for which more than $25 \%$ of registrations are below 12 MPG or above 25 MPG. The remaining sample includes vehicles of limited age, low value, and intermediate fuel economy.

Why not focus on a narrower range of MPG? One answer is sample size. But, equally important, CARS linked both program eligibility and the size of the subsidy to the difference in fuel economy between the clunker and new vehicle. Conditional on having a clunker, the greater the fuel economy of the clunker, the more restricted was the set of new vehicles that qualified. It is reasonable to believe that households with high-MPG clunkers, who faced a limited choice of new cars that would be eligible for the subsidy, were less likely to participate than households with lower-MPG clunkers. In order to estimate the average effect of the program, we do not study responses only for clunkers immediately below the fuel efficiency cutoff. In a robustness exercise discussed in Section 6.5, we restrict the sample to a narrower range of 16 to 21 MPG.

Within our sample we measure CARS eligibility based on the vehicle's fuel economy and purchase date. We assign a vehicle of a given make, model, and model-year to the treatment group if at least $75 \%$ of its registrations have fuel economy of $18 \mathrm{MPG}$ or lower and if it was purchased no later than July 2008. And we assign the vehicle to the control group if at least $75 \%$ of its registrations have fuel economy of 19 MPG or higher or if it was purchased after July 2008. We drop from the sample any vehicles that are not assigned 
by these rules - e.g. vehicles with equal shares of registrations above and below $18 \mathrm{MPG}$ - because there is significant uncertainty over whether they belong in the treatment or control groups. ${ }^{6}$

Table 2 displays summary statistics. Comparing the means of different characteristics, the treatment and control groups look quite similar. The control group consists of slightly newer vehicles that have a somewhat higher probability of having an outstanding loan, but with a slightly lower balance. Households that own vehicles in the treatment group have quite similar income to those that own vehicles in the control group. The unassigned vehicles, which are the majority, look quite different. They are younger, more fuel efficient, and (by construction) more valuable than vehicles assigned to the treatment and control groups.

Turning to our methodology, our main dependent variable is cumulative vehicle purchases associated with a potential trade-in. We measure program responses at the vehicle level, tracking if and when a vehicle is replaced by the purchase or lease of a new vehicle. In a robustness check we also measure new purchases or leases at the household level without conditioning on disposal of an existing vehicle. Because the CE does not explicitly link specific vehicle disposals to replacement vehicle purchases, we apply the following algorithm to match purchases and disposals. We first assume that a purchase or lease is associated with a vehicle disposal if it occurs in the same month as the disposal. If no contemporaneous disposal exists, we then assign the purchase to disposals within one month that are not otherwise assigned. We code the indicator variable Transaction $_{i t}$ to be one if the household disposes of vehicle $i$ within one month of the purchase or lease of a new car in month $t$. We also measure spending by taking the product of Transaction $_{i t}$ and the gross price of the vehicle purchased or leased. When there are multiple disposals that could be associated with a purchase, we divide the purchase equally among the disposals; when there are two purchases associated with a disposal, we include them both. We apply this procedure identically in the treatment and control groups. We then cumulate the purchases or leases (or spending) associated with each vehicle:

$$
\text { Transactions }_{i t}=\sum_{t=\text { July } 2009}^{\text {Month } T} \text { Transaction }_{i t} .
$$

We estimate a separate cross-sectional, vehicle-level regression for each month, T, July 2009 through April 2010:

$$
\text { Transactions }_{i T}=\alpha_{T}+\beta_{T} \text { Clunker }_{i}+\boldsymbol{\sigma}_{\boldsymbol{T}} \boldsymbol{X}_{\boldsymbol{i}}+\varepsilon_{i T},
$$

where Clunker is an indicator variable for whether the vehicle is eligible for CARS. The regression coefficient $\beta_{T}$ measures the cumulative difference - between June 2009 and month $T$ - in the likelihood of purchase for a clunker relative to a close-to-clunker. $\alpha_{T}$ captures common variation in cumulative purchases in the treatment and control groups at each horizon. The additional control variables $\boldsymbol{X}$ relax the assumption of parallel trends between the two groups by allowing for variation in the rate of purchases due to factors, such as household income and vehicle age, that may differ between the treatment and control groups. We vary $\boldsymbol{X}$ to include survey features (interview number), household characteristics (income), and/or vehicle

\footnotetext{
${ }^{6}$ When the purchase date of an owned vehicle is missing, we assume that it had been owned for more than a year since this is much more common in the purchase dates we do observe and because people are more likely to forget purchase dates when they are further in the past.
} 
characteristics (vehicle age and value and MPG). Because $\boldsymbol{\sigma}_{T}$ differs across periods, the slope coefficients on these control variables are allowed to differ by month.

In the second part of our analysis, we look at how the effect of CARS differs across vehicles or households with different characteristics by including an interaction term between $C l u n k e r$ and $\boldsymbol{Z}_{\boldsymbol{i}} \subset \boldsymbol{X}_{\boldsymbol{i}}$ :

$$
\text { Transactions }_{i T}=\alpha_{T}+\beta_{T} \text { Clunker }_{i}+\gamma_{\boldsymbol{T}} \boldsymbol{Z}_{\boldsymbol{i}} \text { Clunker }_{i}+\boldsymbol{\sigma}_{\boldsymbol{T}} \boldsymbol{X}_{\boldsymbol{i}}+\varepsilon_{i T} \text {. }
$$

In this model each $\beta_{T}$ coefficient measures the cumulative difference (up to month $\mathrm{T}$ ) in the likelihood of trade-in for a clunker (relative to a close-to-clunker) conditional on the value of the variables in $\boldsymbol{Z}_{\boldsymbol{i}}$ equaling zero. And $\gamma_{T} \times Z_{i}$ measures the differential change in the probability of purchase for vehicles with characteristic $\boldsymbol{Z}_{\boldsymbol{i}}$. For example, to account for differential sensitivity to CARS based on the available subsidy, we estimate a model that includes an interaction between program eligibility and estimated trade-in value outside of the CARS program. That is, for this model with $\boldsymbol{Z}_{\boldsymbol{i}}=$ Value $_{i}$, the coefficient $\beta_{T}$ measures the program response for the subset of vehicles with zero trade-in value, which then receive a maximum subsidy equal to the CARS rebate. And $\gamma_{T} \times V_{a l u e_{i}}$ measures the change in the probability of purchase for vehicles with higher trade-in values. We also use these specifications to test the importance of liquidity and debt capacity for the response to the CARS program.

While we cannot directly test our identifying assumptions, in Section 6.5 we run two placebo tests to understand whether our treatment and control groups differ in observed ways. First, we check that there is no difference in purchases between our defined treatment and control groups when the CARS program is not run. Using 2008 data, we follow exactly the sample procedures to construct our sample and treatment and control groups, and run our analysis in exactly the same months when of course there was no CARS program. Second, we run our main analysis in the period of CARS with our identical treatment and control groups but with the dependent variable measuring purchases or leases of used vehicles. Both placebo analyses find no effects, and so support our assumption that absent CARS, our treatment and control groups would have behaved similarly.

What exactly does our methodology estimate? This approach estimates the response to having a vehicle that is eligible for CARS instead of a similar vehicle that is not eligible, in the world in which the CARS program was run. This has two implications. First, under the assumption that general equilibrium effects have the same average impact on households with similar vehicles that are eligible and ineligible for CARS, our estimate can be aggregated to reveal the partial-equilibrium impulse response of aggregate demand to the CARS program. Second, our estimates of the temporal dynamics of the program and of the heterogeneity in program impact across household and vehicle characteristics are both conditional on the aggregate outcomes we observe. For example, had the recession not ended when CARS was run, the effects of the CARS program may not have been rapidly reversed or the pattern of its impact across households and vehicles might have been different from what we find. 


\section{The impact of CARS on vehicle purchases}

\subsection{Average impact}

Panel A of Table 3 reports estimates of the impact of the CARS program on new vehicle purchases and leases based on Equation 2 at several horizons and with different sets of control variables. The first column shows estimates without any control variables, reflecting the difference in cumulative purchase rate between the treated clunker vehicles and the otherwise similar close-to-clunker vehicles that were not eligible for the program. The main finding from the first column is that there is a statistically significant and substantial effect of the program, primarily during August 2009. Eligibility for the CARS program increased the rate at which households disposed of an existing vehicle for the purchase or lease of a new vehicle by $0.36 \%$ $(p<0.10)$ by the end of July, $1.22 \%(p<0.01)$ by the end of August and by $1.43 \%(p<0.01)$ by the end of September. During the same period, close-to-clunker vehicles had a disposal rate of $0.5 \%$ toward the purchase or lease of a new vehicle. The rate at which clunkers were traded in for a new purchase or lease therefore nearly quadrupled during the program period, from $0.5 \%$ to $1.9 \%$.

Although the CARS program stopped accepting applications in August, we consider purchases made during September as part of the treatment effect of the program. Our reading of the CE questionnaire is that the reported purchase date could be interpreted as the delivery date, and many CARS purchases entailed September delivery. Further, the evidence on trade-in amounts shown in Figure 1 suggests that CARS purchases were indeed reported in September in the CE data.

The remaining columns of Panel A of Table 3 show that our estimate of the program response is robust to the inclusion of a variety of controls for survey structure (interview number and missing interviews), household characteristics (income), and vehicle characteristics (age and value, and then also fuel efficiency). The estimated impact rises as we increase the number of control variables, although the differences are not statistically significant. The only column with economically noticeably larger estimates is the last column which includes the control for fuel efficiency. Fuel efficiency is obviously highly correlated with the CARS program, and one can see that power substantially declines in the last column when we include fuel efficiency; standard errors increase by $50 \%$.

Turning to dollar spending, Panel B of Table 3 shows the results from estimation of Equation 2 in which the dependent variable is the cumulative dollar amount of new vehicle transactions. Because people with eligible vehicles take advantage of CARS, eligibility caused an average of $\$ 263$ of spending through August and $\$ 327$ through the end of September per eligible vehicle according to the first column of Panel B, and by larger (but not statistically significantly larger) amounts with more control variables.

These dollar amounts are consistent with our estimates of the increase in the number of purchases and what we know about the average purchase price under CARS. Panel $\mathrm{C}$ reports the average price of a new car purchase caused by CARS according to our estimates, calculated by dividing the unconditional expenditure coefficients in Panel B by the incremental purchase probabilities in Panel A. Our estimate of the average price of a new car purchase caused by CARS, $\$ 22,912$ (Panel C, Column 1), is very close to the average

price of all new cars purchased that made use of the program. According to the National Highway Traffic Safety Administration (2009b) report, the average vehicle purchased using the CARS program was $\$ 22,450$. 
Similarly, in the CE data, new vehicle purchases between July and September 2009 with trade-in value of $\$ 3,500$ or $\$ 4,500$ (plotted in Figure 1) have an average purchase price of $\$ 22,283$.

Our estimate of the average impact per eligible vehicle is not directly comparable to the estimates of other studies, which use different sample restrictions and rules for assigning program eligibility. We therefore defer such comparisons to Section 6.6, where we estimate the program's aggregate impact.

\subsection{Economic subsidy}

How responsive were households to the program's economic subsidy? In addition to providing a parameter useful for the design of similar programs, the answer to this question provides an estimate of CARS on the behavior of a household facing a given subsidy, rather than an estimate that is intermediated by sample selection and the distribution of subsidies within any given sample.

Table 4 displays estimates from Equation 3 with an interaction between Clunker and the trade-in value of the vehicle. The economic value of the CARS subsidy is the rebate of $\$ 4,500$ (or, less common, $\$ 3,500$ for a smaller increase in fuel efficiency) less the trade-in value of the vehicle. The first two columns of Panel A show that an eligible vehicle of no value has a two and half percent chance of being traded in under CARS (first row), an effect roughly double the baseline effect in Table 3. The second row shows that each additional $\$ 1,000$ in estimated trade-in value reduces the probability of purchase under CARS by around half a percentage point, so that an eligible make, model, and model-year vehicle worth $\$ 4,500$ is estimated to be no more likely to be traded in during CARS that an equivalent ineligible vehicle. These results are summarized graphically in Figure 2.

The last two columns in Panel A of Table 4 display the results of the same regressions with cumulative value of new vehicles as the dependent variable. Looking at the last column, for each $\$ 1,000$ of used vehicle value, the average value of spending on new vehicles was $\$ 74$ lower. A worthless eligible vehicle generated $\$ 553$ in expected new vehicle transactions, and implied a unit purchase valueof $\$ 21,265$. An eligible vehicle worth $\$ 4,500$ still generated an expected $\$ 220$ in new vehicle purchases or leases.

Is it reasonable to believe that CARS caused increased an rate of purchase for vehicles worth on average $\$ 4,500$ ? It is. There is actually a distribution of trade-in values associated with any make, model, and model year. Since presumably the least valuable vehicles within any model year are the most likely to be traded in under CARS, the average trade-in value may be an overestimate, particularly for vehicles that are marginal, around the $\$ 4,500$ value. Thus, vehicles traded in under CARS that are of a make, model, model-year that are worth $\$ 4,500$ on average are actually worth less and so receive some subsidy for participation in CARS. ${ }^{7}$

To investigate this point further, Panel B of Table 4 reports the results of expanding our sample to include vehicles of more valuable make, model, and model years and allowing for a nonlinear effect of the CARS subsidy on purchasing and spending. In this approach, if these more valuable vehicles are unaffected

\footnotetext{
${ }^{7}$ It also possible that some people were not aware of the trade-in value of their vehicle so that some vehicles worth more than $\$ 4,500$ were traded-in in error. In this case, we would expect that dealers would not trade in the vehicle under CARS, but simply pay the customer $\$ 4,500$ for the vehicle worth more. In our data, since we do not distinguish these cases, such instances would be included in our measure and be a true effect of the CARS program (although potentially an effect that might not survive repeated CARS-type policies). Such a possibility is consistent with the household responses to the employee-pricing-for-everyone sales event of the summer of 2006 which lead to enormous increases in vehicle sales at prices slightly higher than the previous months (Busse, Simester, and Zettelmeyer 2010).
} 
by CARS, the regression coefficients will capture this. The first row of Panel B shows that there is only an economically small and statistically insignificant effect of CARS on vehicles of make, model, and model year worth on average between $\$ 5,000$ and $\$ 6,500$. The coefficients on the indicator variables for different values have the expected pattern, so that the less valuable an eligible vehicle is the more likely it is to be traded in and the more spending it causes in expectation.

\subsection{Household financial constraints}

Households who wanted to participate in CARS either had to have sufficient liquid wealth to purchase the new vehicle outright, or they had to have enough liquidity to make a required down payment, sufficient income in excess of existing debt payments, and a sufficiently high credit score to be approved for financing or a lease. Roughly $80 \%$ of new vehicle purchases are financed, so that for a large majority of households, the ability to buy a vehicle depends on being approved for financing (or a lease) and having the funds necessary for a down payment.

In this section, we use the CE survey data to estimate whether the impact of CARS was amplified by the liquidity provided by the up-front economic subsidy and/or dampened by households' limited debt capacity due to low income, high debt payments, or high mortgage leverage. We find a large amplification of purchases due to the liquidity effect of CARS and little evidence for any reduction in purchases due to limited debt capacity.

We begin by studying how program participation varied with two different measures of liquidity. First, the CE Survey contains information on household indebtedness that allows us to measure differences in liquidity required to participate in the CARS that are distinct from the size of the economic subsidy provided by the program. The CE collects outstanding vehicle debt balances, by month and by vehicle, for the entire survey period. The survey also collects outstanding unsecured debt balances as of the first and final CE interviews. By observing outstanding vehicle debt, we are able to measure differences in liquidity required to participate in the CARS program. For a would-be participant with a loan secured by its clunker, the liquidity provided by CARS was reduced by the amount of the outstanding loan, which the household would have to repay before using the CARS funds as a down payment. Within our regression sample, $5.7 \%$ and $7.2 \%$ have outstanding debt on their eligible and ineligible vehicles, respectively, and $41.2 \%$ of households have outstanding unsecured debt. Second, the CE Survey contains a measure of household liquid assetschecking and savings account balances - as of the final interview. This asset information, however, is missing for a non-trivial share of households and contains significant measurement error: respondents only report balances if they reach the final interview and they do not report balances contemporaneous with the vehicle purchase decision that we analyze. We divide households into terciles: illiquid households have less than $\$ 300$ in liquid assets, low liquidity households have between $\$ 300$ and $\$ 4,500$ in liquid assets, and liquid households have more than $\$ 4,500$.

We find that CARS participation was significantly reduced for households with existing vehicles secured by outstanding loans. As shown in the first column of Table 5, the Clunker coefficient of 2.33 ( $p<$ 0.01 ) indicates that owners of eligible vehicles unencumbered by outstanding loans increased purchases at substantial rates during the CARS program period. The interaction coefficient of $-2.80(p<0.01)$, meanwhile, shows that CARS had a much smaller impact on the probability of an old vehicle encumbered 
by a loan being traded in to purchase a new vehicle. In fact, the point estimates in this first column suggest that there was essentially no response by households with outstanding vehicle loans because CARS provided them only an economic subsidy but insufficient liquidity.

This finding implies a powerful effect of the program's liquidity provision. Notably, the CARS rebate was large enough to alleviate potential down payment constraints for most buyers. The higher rebate amount of $\$ 4,500$ (claimed by $71 \%$ of participants according to National Highway Traffic Safety Administration (2009)) exceeded the total down payment - cash plus trade-in value - on nearly $70 \%$ of observed car purchases during the same time period in our CE sample. Thus, our findings are consistent with the CARS program being massively oversubscribed because the subsidy provided immediate liquidity that could be used for a down payment. To be clear, these results do not imply that the program induced purchases only through the liquidity it provided. The program had effects because it induced purchases through the combination of the subsidy and liquidity, and, for some households, through the subsidy alone.

One might be concerned that households with loans against their old vehicles are different than households that own their vehicles outright. First, households with encumbered vehicles might simply not purchase new vehicles. Figure 3 shows that this is not the case by displaying the trade-in dynamics of clunker and closeto-clunker vehicles that are either securing loans or are owned by households with unsecured debt such as credit card balances. Figure 3.B shows that among vehicles in the control group, those with outstanding loans are traded in for new vehicles at the same rate as vehicles owned by households with unsecured debt. Thus, vehicles used to secure loans are in fact used in the purchase of new vehicles. Figure 3.A shows that among vehicles eligible for CARS, only vehicles associated with unsecured debt are traded in under the CARS program. Clunkers encumbered with debt - and thus unable to benefit from the liquidity provision of CARS - do not respond to the program. This pattern suggests that households that have borrowed against their vehicles can accumulate down payments and thus do buy new cars at rates not unlike those of owners of other old vehicles. But such households, on short notice, may not have been able to come up with the down payment needed to take advantage of the large and unexpected economic subsidy provided by CARS.

A more specific version of this hypothesis is that the presence of debt is reducing household participation in CARS rather the presence of debt secured by the clunker per se. We offer two sets of results to evaluate this alternative to our interpretation. First, we find that CARS take-up is not reduced for households with unsecured loans. The second column of Table 5 shows that the muted program response is not due to the existence of debt in general or to the fact that households with debt are somehow different (e.g. have lower incomes, or they just do not buy new vehicles). The presence of debt that does not secure a vehicle does not mute program participation; the interaction coefficient of 0.27 is small and statistically insignificant. Second, we show that the estimated decline in CARS participation for encumbered vehicles is robust to controlling for measures of the household's debt capacity and mortgage leverage (see Appendix Table A3). These findings are consistent with a difference in program response due to the liquidity requirement for encumbered clunkers rather than a general difference in indebtedness or borrowing capacity.

The remaining columns of Table 5 control directly for the difference in the effect of CARS related to other factors that are possibly correlated with having a loan secured by the clunker, such as income, the value of the clunker, and existing liquidity. Our concern is that poorer households may be more likely to have vehicle loans and also may be generally less likely to purchase new vehicles. Alternatively, our measured 
effect of an existing loan secured by the vehicle might be due to a correlation between existing auto debt and other variables such as liquid assets or the vehicle value (and thus the effective subsidy). An initial piece of evidence against this concern is that the likelihood of having a secured loan has a low correlation with potential confounding variables. The only variables for which the correlation exceeds 0.05 in magnitude are liquid assets (-0.058) and having an unsecured loan (0.058). Consistent with this pattern, the third column of Table 5 shows that such factors are not driving the result; we include interactions with income and vehicle value and continue to find a distinct decline in purchases associated with encumbered vehicles. In the final two columns, we consider whether there is an important role for a loan on a vehicle after controlling for liquidity directly, which we measure as the amount in checking and savings accounts. In sum, the presence of a loan secured by the potential trade-in continues to have a large negative effect on participation in the CARS program even after controlling for liquid wealth and other covariates. These effects are also robust to a number of further checks and placebo tests described in Section 6.5.

The difference in responses to CARS across households with different levels of liquid assets provides further evidence, albeit statistically weak evidence, about the role of liquidity in program participation. The fourth and fifth columns of Table 5 show that we unfortunately do not have much power to measure these differences (at least in part due to the well-known mis-measurement and missing asset data in the $\mathrm{CE}$ ). However, point estimates suggest that households with very little liquidity, less than $\$ 300$, and households with lots of liquidity, more than $\$ 4,500$, were both less likely to take up CARS. Households with high levels of liquid wealth respond less to CARS (although not statistically significant), consistent with their having liquidity without CARS and therefore benefitting less from the liquidity provided by the program. The behavior of households with low liquid wealth is less consistent with an important role for liquidity provision, although liquid assets are poorly measured and this result is statistically weak.

Having established that liquidity provision was crucial to the CARS program uptake, we now turn to studying the role of debt capacity. Did the ability of households to qualify for loans based on paymentto-income requirements affect response to the program? From the income and balance sheet information reported in the $\mathrm{CE}$, we construct a debt payment-to-income ratio (the sum of mortgage and vehicle debt payments as a fraction of income) and a mortgage leverage ratio (the total mortgage balance as a fraction of the estimated home value). We then test whether the response to CARS varies with income and indebtedness. Households with more income and home equity have more capacity to repay or secure additional borrowing. If the supply of credit were constraining CARS participation, one would therefore expect limited participation by households with low incomes, high payments-to-income ratios and high mortgage leverage.

Table 6 presents the results of our analyses. First, as shown in the first column, the baseline effect of the CARS program remains and there is little statistical or economic difference in the impact of CARS across income terciles. Households in the bottom tercile of the sample, with annual after-tax income below $\$ 24,000$, still respond strongly to the program. Their purchases increase by a statistically significant $1.76 \%$ when they own a clunker rather than a close-to-clunker. ${ }^{8}$ Second, we measure each household's capacity to take on additional monthly payments before reaching a payment-to-income ratio of $1 / 3$ or greater. As shown in the second column of Table 6, CARS participation is actually highest for households with the least debt capacity,

\footnotetext{
${ }^{8}$ This effect is calculated by adding the 1.97 coefficient on Clunker with the -0.21 coefficient on the ClunkerIncome Bottom Tercile interaction.
} 
although this effect is again statistically weak. While it may be a statistical fluke, it does not appear that high existing debt levels constrained participation. Finally, we examine the impact of existing mortgage debt. The last two columns show that both homeowners without mortgages and those with loan-to-value ratios in excess of $50 \%$ were more likely to participate in CARS, although as before this result is statistically insignificant. In the final specification, when we sum the coefficients on Clunker and its interaction with the indicator for negative home equity, we see that homeowners increased purchases by $1.66 \%$ even when they lacked equity to support further mortgage borrowing. In each of these models, we lack the statistical power to draw strong conclusions on how responses varied with debt capacity within our sample. Nevertheless, we find strong CARS participation among the various subsets of households for which debt capacity is most limited, which suggests that debt capacity did not substantially constrain CARS participation.

Why did debt capacity play so limited a role? One possible reason is that, given a large enough down payment, lenders were willing to finance purchases based on collateral value of the new vehicle. Automobiles provide solid collateral that is easier to repossess and re-sell than a home for example, and the CARS subsidy alone provides a $20 \%$ down payment at the average new car price of vehicles purchased using CARS.

However, an important issue to consider is whether measurement error in debt payments and income prevent us from identifying borrowing constraints. Our measure of debt payment-to-income is similar to the measure that Johnson and Li (2010) analyzes using both the CE survey and the Survey of Consumer Finances (SCF). That study presents two relevant findings. First, households in the SCF are substantially more likely to be turned down for credit when they have a high payment-to-income ratio, which indicates that survey-based payment-to-income ratios can effectively measure borrowing constraints. Second, the study validates, to some extent, the quality of the CE liability data by showing that the distribution of debt payment-to-income is remarkably similar in the SCF and CE samples. So, while we cannot rule out the possibility that measurement error is obscuring a debt capacity constraint in CARS participation, the evidence from prior work suggests that the $\mathrm{CE}$ is measuring real variation in debt capacity.

\subsection{Intertemporal substitution}

Having analyzed the contemporaneous impact of the CARS program, we now turn to analyzing the longer run response after the program ended. Figure 4.A and Appendix Table A1 display expanded versions of the results reported in Panel A of Table 3. Figure 4.A plots the difference in the cumulative share of trade-ins for new vehicles between the treatment group of eligible vehicles and the similar group of ineligible vehicles from the a July 2009 to April 2010 (Figure 4.B plots each of these series separately.) The figures reveal two points about the dynamics of the response to CARS.

The first finding is that the increase in purchases caused by CARS lasted for a few months - the effect of CARS was not immediately reversed by lower sales in the few months that followed the program. Our point estimates suggest that the effect of CARS on new vehicles transactions actually continued to rise until November, although this rise is statistically and economically small. We do not treat this increase as part of the main effect of the CARS program and suspect it is due to statistical measurement error.

The second main finding in Figure 4 is that following November 2009, there is a rapid reversal in the differential cumulative purchases between households with clunkers and those with close-to-clunkers. The effect of the CARS program reverses quickly, so that by January 2010, there is no longer a statistically signif- 
icant effect of CARS. By March 2010, the point estimate of the effect of CARS on new vehicle transactions is estimated to be zero, and by April it is slightly negative.

While this result confirms the intertemporal substitution documented in both Mian and Sufi (2012) and Hoekstra, Puller, and West (2016), our evidence is comparatively statistically weak. The shortcoming of the $\mathrm{CE}$ data is that households enter the survey on a rolling monthly basis and remain for only 12 months. As a result, roughly 1/12th of the households from the June 2009 cohort exit the survey in each month, leading to greater statistical uncertainty at longer horizons. Indeed, Figure 4.B shows that much of the spending reversal that we find relates to a decline in cumulative purchases within the treatment group, which is impossible in a fixed cohort but arises in our sample due to the small sample and the attrition of treatment group members that happened to purchase new vehicles.

Would we expect a similar level of near-complete reversal in demand in future CARS-type programs? It is possible that intertemporal substitution was so large in part because CARS was terminated early due to funding. The households that were able to take advantage of CARS quickly may have disproportionately been those who were preparing to purchase a vehicle in the near term anyway. Another factor possibly affecting the measured reversal in demand is that CARS was implemented rapidly after announcement. If CARS reduced the relative supply of the types of vehicles that eligible households would choose, then the measured reversal might partly be due to a low relative supply of vehicles typically chosen by eligible households relative to vehicles typical chosen by the control group. But this requires different tastes across groups and little substitution. Further, CARS was implemented when the automobile industry was producing well below capacity, although also when it was just emerging from bankruptcy.

\subsection{Placebo tests and robustness}

We cannot directly test our identifying assumption that vehicle purchases would have been similar in the treatment and control groups in the absence of CARS in the summer of 2009. However, we can test for evidence of bias in our estimation procedure by checking that our methodology correctly measures that CARS had no effect in periods or for outcomes that should be unaffected by CARS. First, we check whether there was any differential purchase or lease of new vehicles in June of 2009, before the program started which might indicate bias in our estimated program impact. Second, we check whether there is any difference in purchases between similarly defined treatment and control groups over the same months of 2008, a year in which the CARS program was not run. Third, we check whether there is any difference in transactions during the CARS period for used vehicles that would not have qualified for the CARS subsidy.

One might have been concerned that the large response of CARS-eligible vehicles was in part due to households delaying purchase from preceding months to take advantage of the CARS rebate. We reestimate Equation 2 with the dependent variable measuring purchases during June 2009, the month before the program. We find an economically small and statistically insignificant effect of the CARS in June of 0.21 with a standard error of 0.25 (reported in Table A2 in the Appendix). The fact that we estimate a positive rather than negative coefficient suggests (somewhat surprisingly) that households did not significantly delay purchases prior to CARS.

Second, using 2008 data, we follow identical sample procedures to construct treatment and control groups, and run our analysis in exactly the same months of 2008, during which the CARS rebate was not 
available. Figure 5 plots the coefficients starting in July 2008 and is completely analogous to Figure 4.A which starts in July 2009. The treatment and control groups purchase or lease new cars at similar rates in July, August, and September of 2008. Although this difference is statistically weak, if anything, the control group has a slightly higher rate of purchase. Panel A of Table 7 shows that we also find no difference in purchases through September of 2008 when we include the full set of control variables.

Third, we estimate Equation 2 but with the dependent variable replaced by cumulative purchases or leases of used vehicles during the CARS period. Panel B of Table 7 shows that there is no evidence of any difference in purchases of used vehicles caused by CARS: all coefficients are less than one standard error distance from zero. Thus our procedure does not appear to be picking up any differences between treatment and control group in the propensity to purchase vehicles in general that would apply to both new and used vehicles. In sum, these placebo tests do not reject the validity of our identifying assumptions and the resulting estimates of the impact of the CARS program.

Our results are also robust to a number of alternative reasonable assumptions about the sample and the dependent variable, as we show in Appendix Table A2. One might be concerned, for example, that our results are driven by vehicles at the very low and high ends of MPG in our sample, which may be quite different. When we reduce the sample size by narrowing the range of fuel efficiency in our sample to 16 to 21 MPG, we find a slightly larger program response of $1.74 \%$ through September, but we lose statistical power, as the standard error more than doubles to 0.97. Another concern is that our sample restriction to make, model and model-years with less than $\$ 5,000$ trade-in value omits some vehicles that are worth much less than the average for their make, model and model year and for which CARS may have an effect. In an expanded sample of vehicles with average trade-in value less than or equal to $\$ 6,500$, we find an estimated effect of CARS of a 1.61\% $(p<0.01)$ increased probability of purchase. We also find similar results when we conduct our analysis at the household level rather than the vehicle level, an alternative assumption that reduces the effective variation in the data slightly (see column 4 in Appendix Table A2). A third concern is that CARS causes some people to scrap an old vehicle to make a purchase that they otherwise would have made while continuing to hold on to their old vehicle. Such behavior could bias upward our measured effect of CARS on purchases. For such people taking advantage of CARS, we would count the purchase because of the associated trade-in, while for such people with ineligible vehicles, we would not count their purchase because it would not be associated with a trade-in. To investigate this possibility, we replace our dependent variable with the cumulative purchases or leases of all new vehicles rather than just those associated with the disposal of a vehicle by a household. Instead of a lower effect of CARS however, we find a slightly larger measured effect. In sum, our results are generally robust to reasonable alternatives.

Finally, we provide further evidence that our findings on the importance of liquidity provision by CARS are not instead driven by other factors. As discussed in the previous section, we obtain our main liquidity findings by comparing the response to CARS of potential trade-in vehicles with and without outstanding loans. If the difference in trade-in rates between cars with and without outstanding loans were driven by something other than the differential liquidity provided to these groups by the CARS program, then these differences should also appear in our placebo analyses using purchases in 2008 and purchases of used vehicles. Including the interaction with outstanding loan in each placebo test, the presence of a loan securing a vehicle has a statistically insignificant (and if anything positive) effect on participation in pseudo-CARS 
(see Table 7). We also address the concern that our estimates of treatment effect heterogeneity with respect to liquidity may actually be capturing treatment heterogeneity in other dimensions. As we show in Table A3 of the Appendix, our findings are robust to allowing for the response to CARS to also vary with income, existing payment-to-income ratio, and mortgage loan-to-home value terciles. Finally, we continue to find a strong negative effect of having a loan secured by a vehicle when we control for a broader measure of wealth rather than just liquid wealth.

In summary, our estimates of the response to the CARS program appear to be well identified and not driven by several possible biases or sources of mis-measurement. We now turn to using these estimates to study the aggregate effects of the program.

\subsection{Partial-equilibrium impact on aggregate demand for vehicles}

We use our vehicle-level estimates to draw inferences about the aggregate impact of the CARS program on the number and dollar value of vehicle purchases. Below, we describe this calculation and compare our estimate of aggregate impact to the estimates of prior studies.

First, we estimate the number of CARS-eligible vehicles in the U.S. Assuming vehicle ownership is unrelated to $\mathrm{CE}$ data being missing, we use the $\mathrm{CE}$ sample weights scaled up for missing data to estimate that there were $35,423,323$ of CARS-eligible vehicles with value less than $\$ 5,000$. We also calculate an alternative measure using the Polk data on registrations merged with vehicle values from Edmunds. This calculation yields a similar number: 38,737,677 such vehicles.

Second, we multiply the number of CARS-eligible vehicles by the number of purchases per CARS-eligible vehicle estimated in Section 6.1. According to the first column of Table 3, the CARS program raised the probability of purchase by $1.43 \%$ over the three month period from June to September 2009. To calculate the number of vehicle purchases at the time of the program caused by the CARS, we multiply the percentage increase in purchases per CARS-eligible vehicle by the total number of CARS-eligible vehicles, which implies that the CARS program directly caused an additional 506,553 purchases or leases of new vehicles between July and September 2009 based on our CE estimate. The corresponding number from the Polk-Edmunds total is 553,949 .

Third and finally, we calculate the impact on aggregate demand using the average reported purchase price in the CE data for new vehicle purchases between July and September 2009 with trade-in value of $\$ 3,500$ or $\$ 4,500$. This average purchase price of $\$ 22,283$ is very close to the National Highway Traffic Safety Administration (2009b) report of the average MSRP of vehicles purchased using the CARS program, which is $\$ 22,453$. These numbers imply that the CARS program raised demand by $\$ 11$ billion in incremental purchases or leases $(506,553$ purchases x $\$ 22,283$ per purchase) according to our CE-based estimate or $\$ 12$ billion according to our Polk-Edmunds based estimate. According to the National Highway Traffic Safety Administration (2009), just under half of the vehicles purchased were produced domestically, and vehicles purchased that were produced domestically were slightly more expensive than those that were imported.

Our baseline estimates therefore imply that the CARS program increased demand (meaning a partialequilibrium, accounting estimate) for durable goods by $\$ 11$ billion in the third quarter of 2009 , or by $\$ 44$ billion at an annual rate. In terms of the expenditure accounts, roughly half of this was an increase in demand for imported vehicles, and potentially some of the demand was met through reduced inventory 
investment (of imported and domestically-produced goods), so that the impact on production was almost surely less than the full $\$ 44$ billion (again in a partial-equilibrium, accounting sense). Due to inventory reduction, the accounting effect on national income is likely larger than the production-side effect and may be closer (at least contemporaneously) to the complete $\$ 44$ billion. To put these numbers in perspective, GDP increased by $\$ 43.7$ billion in the third quarter of 2009 , coinciding with the end of the recession (the NBER dates the trough as June). Real GDP had fallen $\$ 200$ billion per quarter in the two worst quarters of the recession - the last quarter of 2008 and the first quarter of 2009 - and it fell by $\$ 43.5$ billion in the second quarter immediately before CARS.

Our estimate of the aggregate impact is within the range of estimates reported in prior studies, but at the high end of the range. Based on transactions in other periods and the prevalence of CARS-eligible vehicles, Council of Economic Advisors (2009) estimates that 240,000 of the purchases made under the CARS program would have occurred anyway, so that CARS caused 440,000 additional purchases. ${ }^{9}$ Based on a survey of households that participated in CARS, National Highway Traffic Safety Administration (2009) estimates that CARS caused an additional 600,000 purchases. Mian and Sufi (2012) estimates that CARS caused between 340,000 and 400,000 new purchases. However, their analysis may underestimate the program's impact. They assume CARS caused no purchases in cities with a bottom-decile share of clunkers, despite the fact that these cities still had 5.8 clunkers per 2004 purchase (compared to a city average of 9.9 ).${ }^{10} \mathrm{Li}$, Linn, and Spiller (2013) consider the experience of Canada as a counterfactual to the United States and estimate 370,000 incremental purchases due to CARS.

\section{Conclusion and discussion}

This paper uses household expenditure data to evaluate the CARS stimulus program and to investigate whether financial frictions dampened the response to the program. To identify the program impact, we compare purchases by owners of eligible vehicles to purchases by owners of ineligible vehicles with similar value but fuel economy above the CARS program cutoff. We also use information on households' assets and liabilities, unique to our evaluation of CARS, to understand whether take-up varied with liquidity, debt capacity, and the size of the program subsidy.

Our estimates of the average effect of the CARS program lie within the range of previous estimates. We provide new evidence that take-up increased with the size of the economic subsidy, which was the official credit less the value of the trade-in. In aggregate, we find that during the period of the program, purchases using CARS-eligible vehicles doubled relative to the comparison group, generating roughly $\$ 11$ billion in additional (partial-equilibrium) demand from a Federal outlay of only $\$ 2.9$ billion. However, consistent with theory and previous research, this large effect was due to short-term intertemporal substitution in response to the temporary price subsidy: although we have limited power, our point estimates suggest that cumulative (partial-equilibrium) auto sales were unaffected by the program seven months after its initiation.

\footnotetext{
${ }^{9}$ At the time of the program, however, the economy was just emerging from the Great Recession, so coincident changes to incomes, wealth, and uncertainty could also be responsible for deviations from the estimated path of sales.

${ }^{10}$ If one assumed that CARS had an effect on purchases in these bottom-decile cities, this would raise the estimated aggregate effect by a factor of $9.9 /(9.9-5.8)$, to 893,000 .
} 
Our most novel finding is that the large response to CARS was significantly reliant on the liquidity it provided. Since roughly $80 \%$ of new vehicle purchases are financed, a household's ability to borrow was critical for its participation in CARS. By offering a large credit available at the time of sale, CARS provided liquidity that could be used to meet the down payment requirement typical of a new vehicle loan. For households with preexisting loans on their potential trade-in vehicles, however, participation required further liquidity to immediately repay the loan on the scrapped vehicle. Consistent with binding liquidity constraints, we show that program participation decreased significantly for these households, even when controlling for any differences in their income, liquid assets, existing car value and the economic subsidy offered by trading it in, and baseline propensity to purchase new vehicles. In contrast, while statistical power is limited, we find no measurable differences in take-up for households with unsecured outstanding debts, nor any evidence that household responses were constrained by debt capacity. Households with modest income, high debt payment-to-income ratios, and high mortgage leverage all show strong responses to the program. By making possible a large down payment, it is possible that CARS facilitated loans to risky borrowers on the strength of the collateral rather than the borrowers' ability to repay.

Our findings offer lessons for the design of similar programs. Our findings suggest that responses to such programs are larger if subsidies are timed so that they can contribute to down payments and alleviate liquidity constraints, rather than being given as tax incentives to be paid at later dates. We would also expect significantly lower responses if subsidies were insufficient to contribute a substantial portion of the typical down payment. While larger subsidies would draw in more households, we would expect the per dollar responses to be lower as additional funds beyond typical down payment amounts would only have the subsidy benefit and not also a liquidity benefit. 


\section{REFERENCES}

Aaronson, D., S. Agarwal, and E. French (2012). The spending and debt response to minimum wage hikes. American Economic Review 102(7), 3111-3139.

Adams, W., L. Einav, and J. Levin (2009). Liquidity constraints and imperfect information in subprime lending. American Economic Review 99(1), 49-84.

Adda, J. and R. Cooper (2000). Balladurette and Juppette : A Discrete Analysis of Scrapping Subsidies. Journal of Political Economy 108(4), 778-806.

Agarwal, S., C. Liu, and N. S. Souleles (2007). The Reaction of Consumer Spending and Debt to Tax Rebates-Evidence from Consumer Credit Data. Journal of Political Economy 115(6), 986-1019.

Agarwal, S. and W. Qian (2014). Consumption and debt response to unanticipated income shocks: Evidence from a natural experiment in Singapore? American Economic Review 104(12), 3841-3884.

Auerbach, A. J. and K. Hassett (1992). Tax policy and business fixed investment in the United States. Journal of Public Economics 47(2), 141-170.

Bar-Ilan, A. and A. S. Blinder (1992). Consumer Durables: Evidence on the Optimality of Usually Doing Nothing. Journal of Money, Credit and Banking 24(2), 258-272.

Benmelech, E., R. R. Meisenzahl, and R. Ramcharan (2016). The Real Effects of Liquidity During the Financial Crisis: Evidence from Automobiles. Quarterly Journal of Economics, Forthcoming.

Berger, D., N. Turner, and E. Zwick (2016). Stimulating Housing Markets. Chicago Booth Research Paper No. 16-16.

Berger, D. and J. Vavra (2015). Consumption Dynamics During Recessions. Econometrica 83(1), 101-154.

Broda, C. and J. A. Parker (2014). The economic stimulus payments of 2008 and the aggregate demand for consumption. Journal of Monetary Economics 68, S20-S36.

Busse, M. R., C. R. Knittel, J. Silva-Risso, and F. Zettelmeyer (2012). Did cash for clunkers deliver? The consumer effects of the car allowance rebate system. Working paper.

Busse, M. R., D. I. Simester, and F. Zettelmeyer (2010). "The Best Price You'll Ever Get": The 2005 Employee Discount Pricing Promotions in the U.S. Automobile Industry. Marketing Science 29, 268290.

Caballero, R. J. (1993). Durable Goods: An Explanation for Their Slow Adjustment. Journal of Political Economy 101(2), 351-384.

Caballero, R. J., E. M. R. A. Engel, and J. Haltiwanger (1997). Aggregate Employment Dynamics: Building from Microeconomic Evidence. American Economic Review 87(1), 115-137.

Council of Economic Advisors (2009). Economic Analysis of the Car Allowance Rebate System ("Cash for Clunkers"). Retrieved from https://www.whitehouse.gov/administration/eop/cea/CarAllowanceRebateSystem.

Desai, M. A. and A. Goolsbee (2004). Investment, Overhang, and Tax Policy. Brookings Papers on Economic Activity 2004(2), 285-355. 
Di Maggio, M., A. Kermani, and R. Ramcharan (2014). Monetary Policy Pass-Through: Household Consumption and Voluntary Deleveraging. Columbia Business School Research Paper No. 14-24.

Edgerton, J. (2010). Investment incentives and corporate tax asymmetries. Journal of Public Economics 94 (11-12), 936-952.

Hoekstra, M., S. J. Puller, and J. West (2016). Cash for Corollas: When Stimulus Reduces Spending. American Economic Journal: Applied Economics, Forthcoming.

House, C. L. and M. D. Shapiro (2008). Temporary investment tax incentives: Theory with evidence from bonus depreciation. American Economic Review 98(3), 737-768.

Johnson, D. S., J. A. Parker, and N. S. Souleles (2006). Household expenditure and the income tax rebates of 2001. American Economic Review 96(5), 1589-1610.

Johnson, K. W. and G. Li (2010). The debt-payment-to-income ratio as an indicator of borrowing constraints: Evidence from two household surveys. Journal of Money, Credit and Banking 42(7), 13731390.

Krebs, M. (2009). New Math: Cash for Clunkers Numbers Don't Add Up. Edmunds.com Auto Observer. Retrieved from http://www.edmunds.com/autoobserver-archive/2009/09/new-math-cash-forclunkers-numbers-dont-add-up.html.

Li, S., J. Linn, and E. Spiller (2013). Evaluating "Cash-for-Clunkers": Program effects on auto sales and the environment. Journal of Environmental Economics and Management 65(2), 175-193.

Mian, A. and A. Sufi (2012). The effects of fiscal stimulus: Evidence from the 2009 cash for clunkers program. Quarterly Journal of Economics 127(3), 1107-1142.

National Highway Traffic Safety Administration (2009). Consumer Assistance to Recycle and Save Act of 2009. Report to Congress.

Parker, J. A., N. S. Souleles, D. S. Johnson, and R. McClelland (2013). Consumer spending and the economic stimulus payments of 2008. American Economic Review 103(6), 2530-2553.

Rampini, A. (2016). Financing Durable Assets. NBER Working Paper No. 22324.

Zwick, E. and J. Mahon (2016). Tax Policy and Heterogeneous Investment Behavior. American Economic Review, Forthcoming. 
Panel A: New Vehicle Purchases

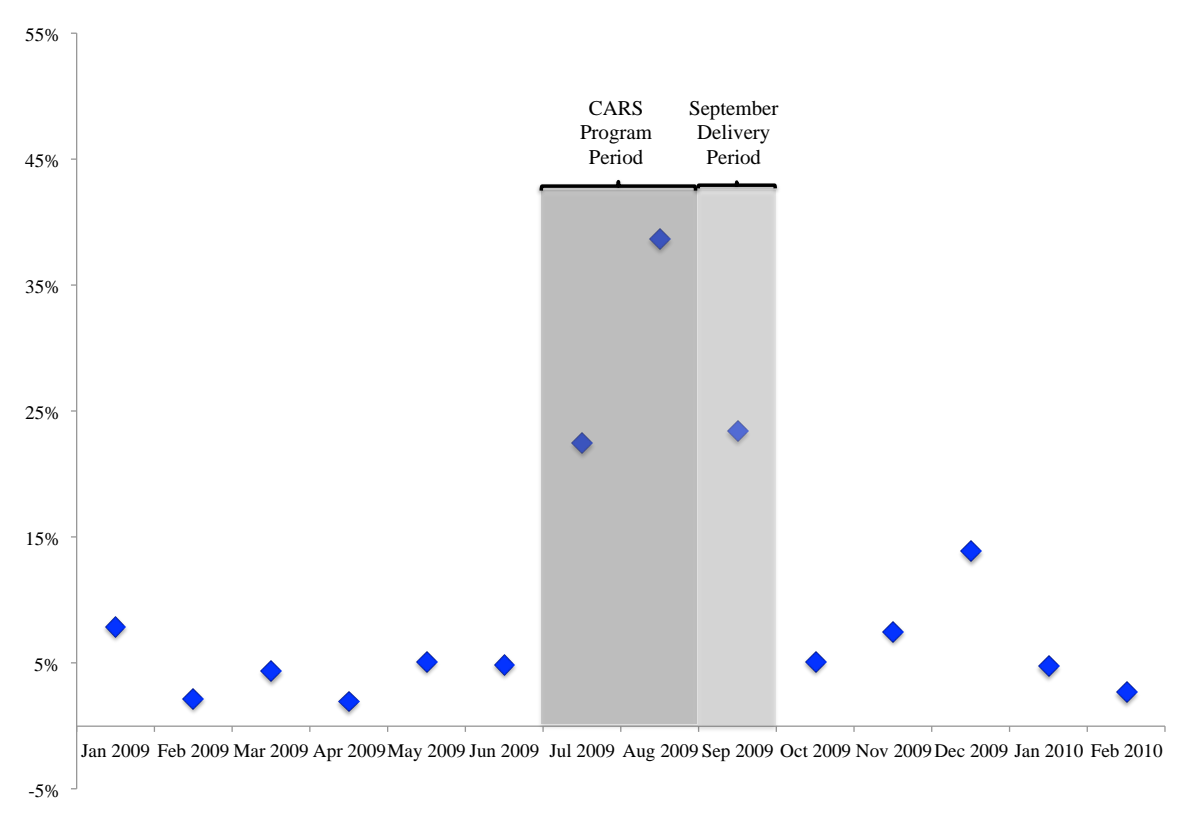

Panel B: Used Vehicle Purchases

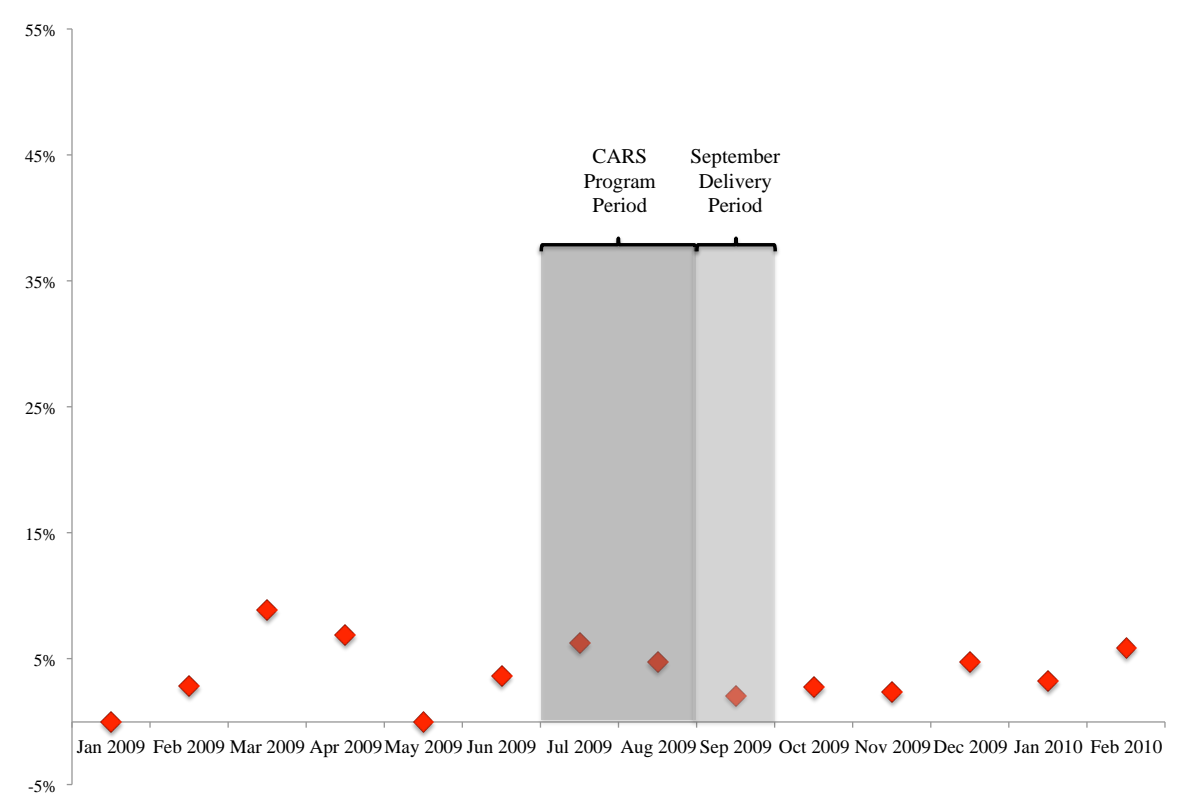

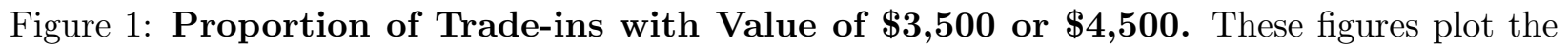
proportion of trade-ins with value of $\$ 3,500$ or $\$ 4,500$ on new (Panel A) and used vehicle (Panel B) purchases between January 2009 and February 2010. The x-axis corresponds to the month of the purchase. The sample is constructed from CE survey responses between 2009 through 2013, and includes transactions that occurred during the respondents' participation in the survey and transactions that were reported retrospectively in interviews between 2010 and the first quarter of 2013. 
Panel A: CARS Response: Purchase Rate

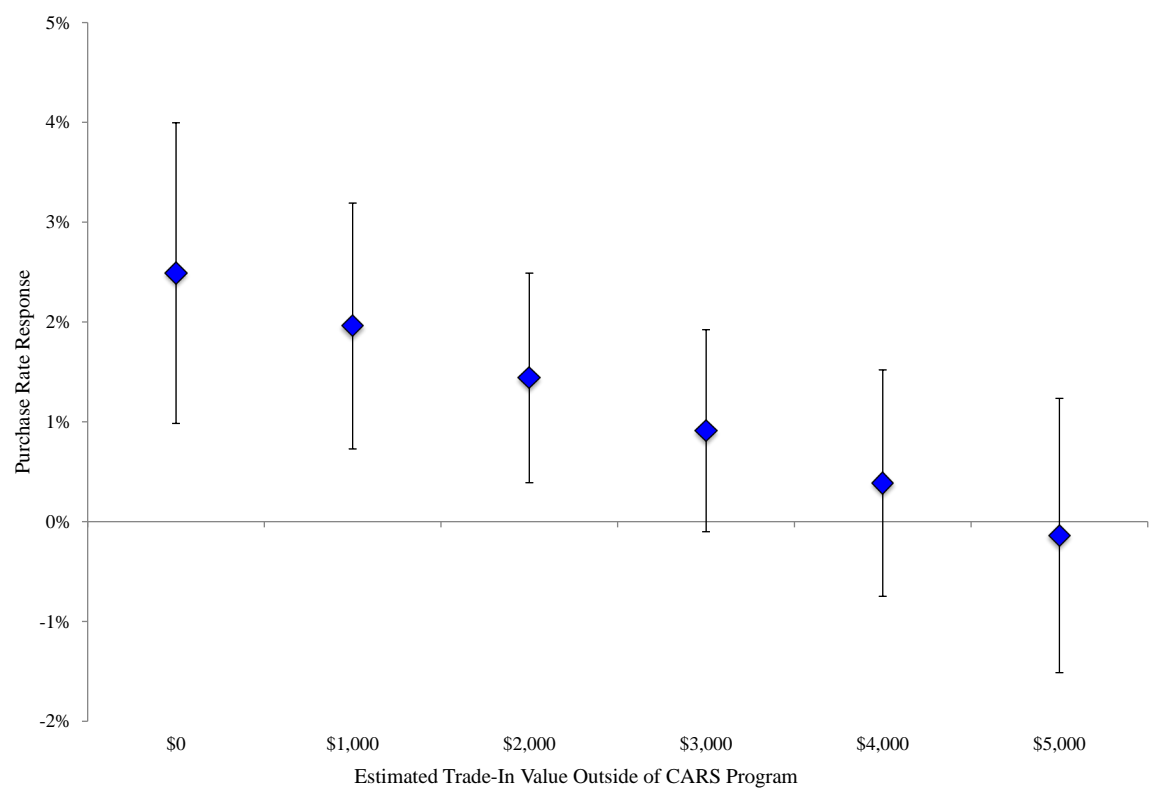

Panel B: CARS Response: Dollars

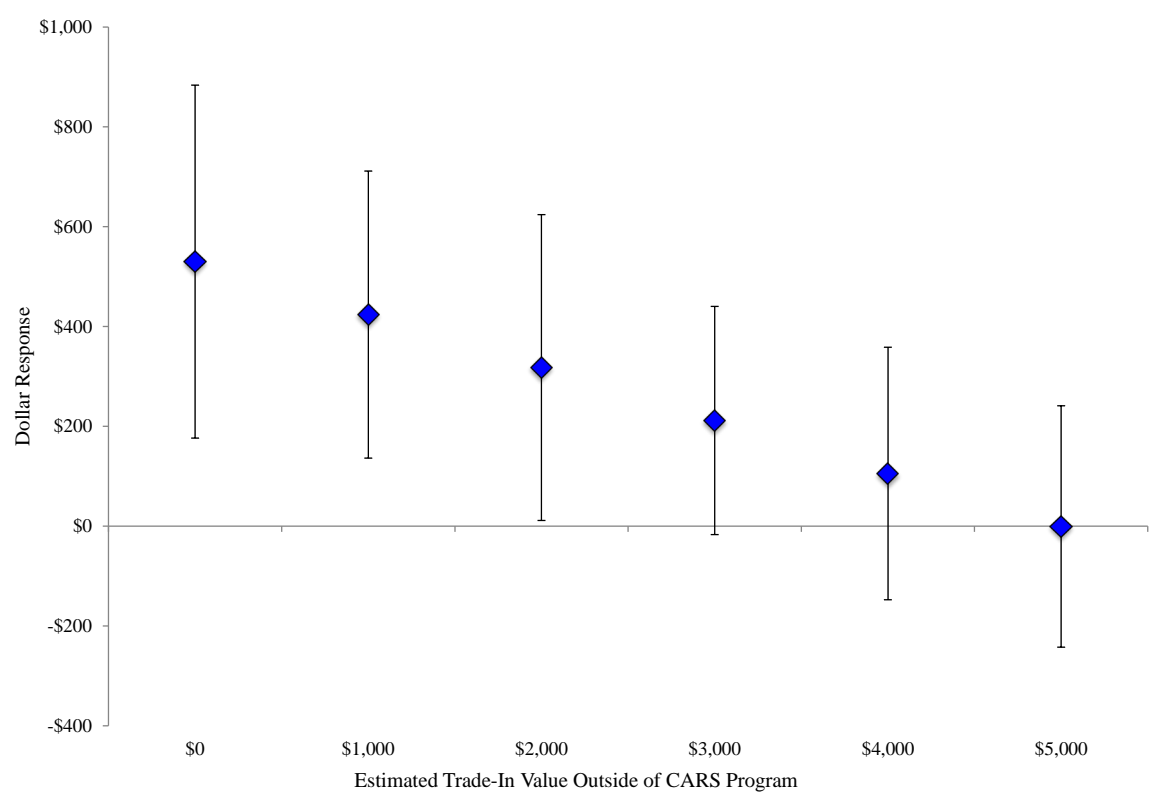

Figure 2: CARS Response by Trade-in Value. This figure plots the CARS response for eligible vehicles of different trade-in values. The y-axis is change in the rate of new vehicle purchases or leases associated with CARS. The point estimates and confidence intervals are calculated from the model reported in the first column of Table 4, Panel A. 
Panel A: Treatment Group Cumulative Purchase Rate with Vehicle Loan or Unsecured Loan

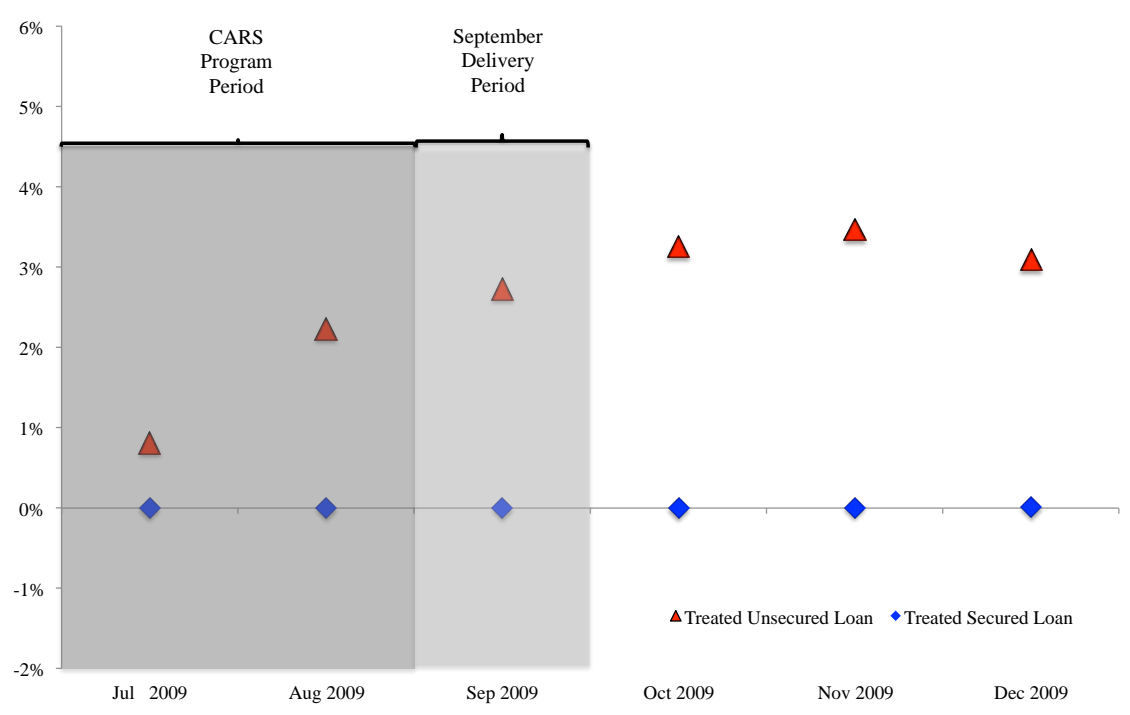

Panel B: Control Group Cumulative Purchase Rate with Vehicle Loan or Unsecured Loan

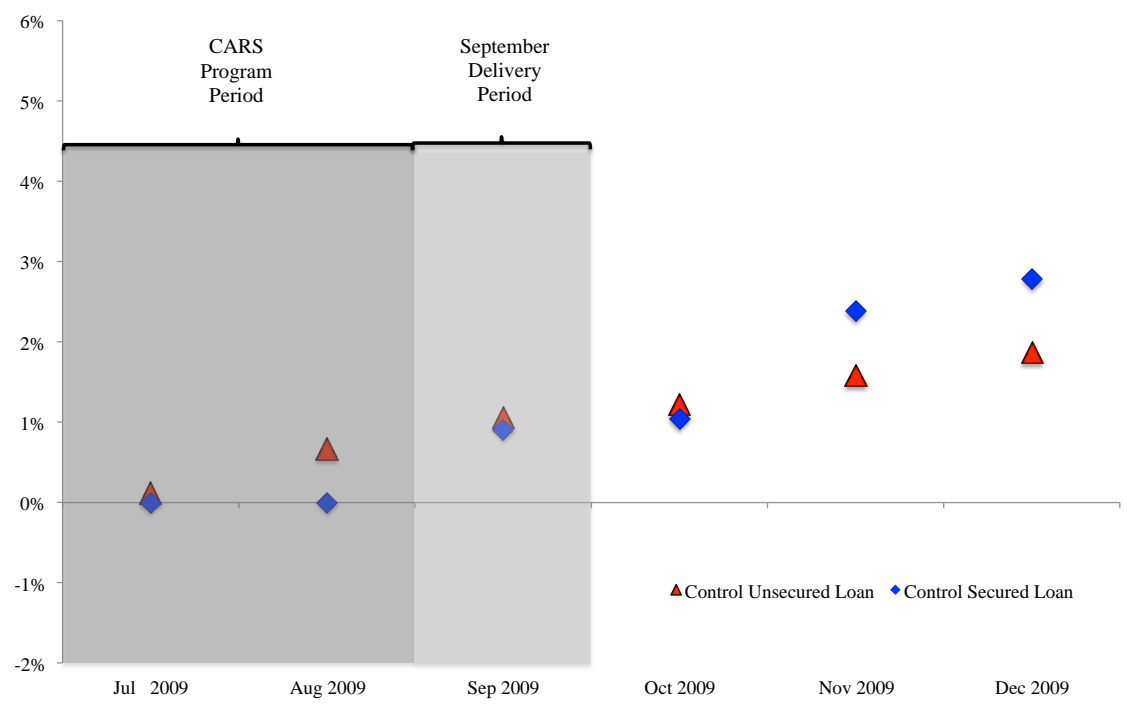

Figure 3: CARS Response and Outstanding Debt. This figure plots the cumulative rate of new vehicle purchases or leases in four subgroups of the main sample, defined by CARS eligibility ("treated" or "control") and household indebtedness. Within each panel, we report cumulative purchases or leases separately for vehicles encumbered by a loan and vehicles owned by households with outstanding unsecured loans. To obtain these estimates we include interactions of the Clunker indicator with indicators of secured and unsecured debt balances. 
Panel A: Cumulative Difference between Treatment and Control Groups

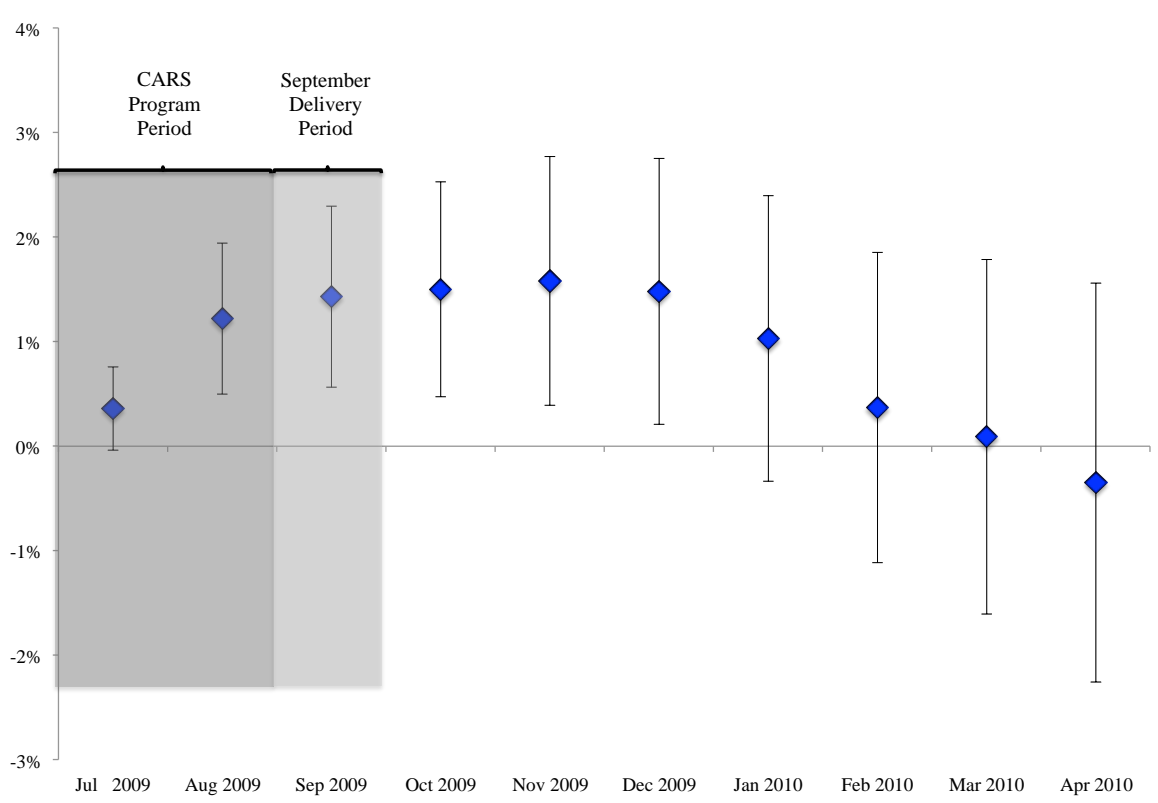

Panel B: Cumulative Purchases in Treatment and Control Groups

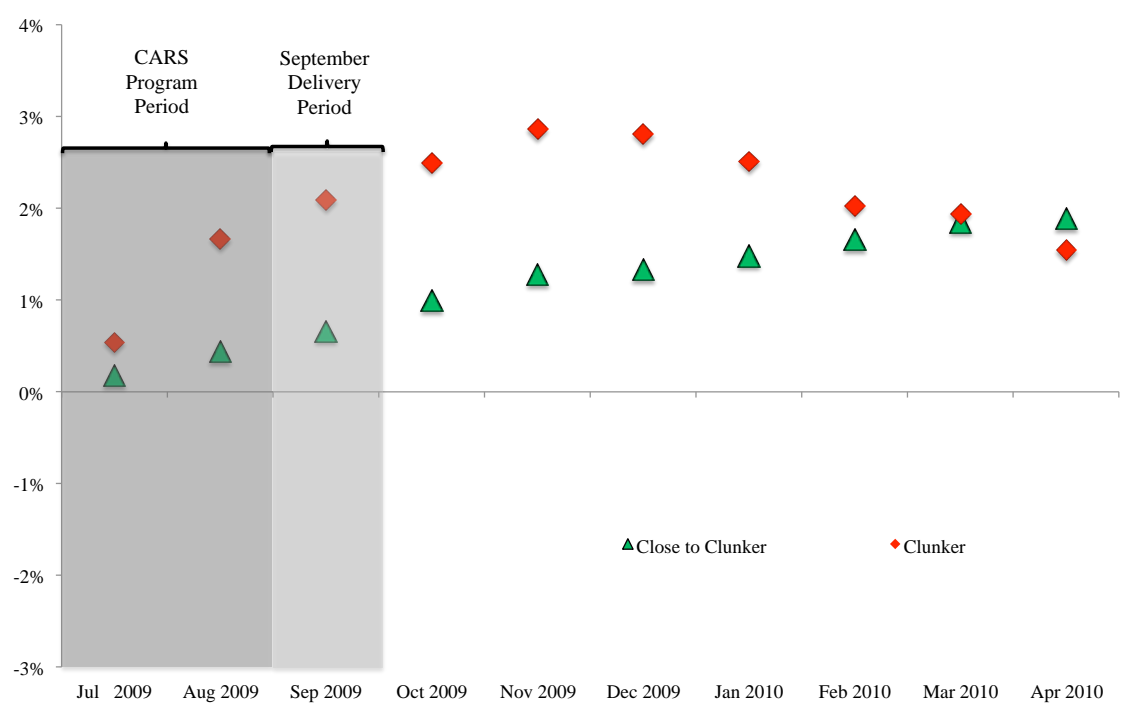

Figure 4: Cumulative Impact of CARS on Rate of New Vehicle Purchases. Panel A plots the cumulative difference (since June 2009) in the rate of new vehicle purchases for CARS-eligible vehicles compared to similar ineligible vehicles. The lines indicate the $95 \%$ confidence intervals, computed with clustering at the household level. Panel B plots the cumulative rate of purchases for eligible and ineligible vehicles separately. 


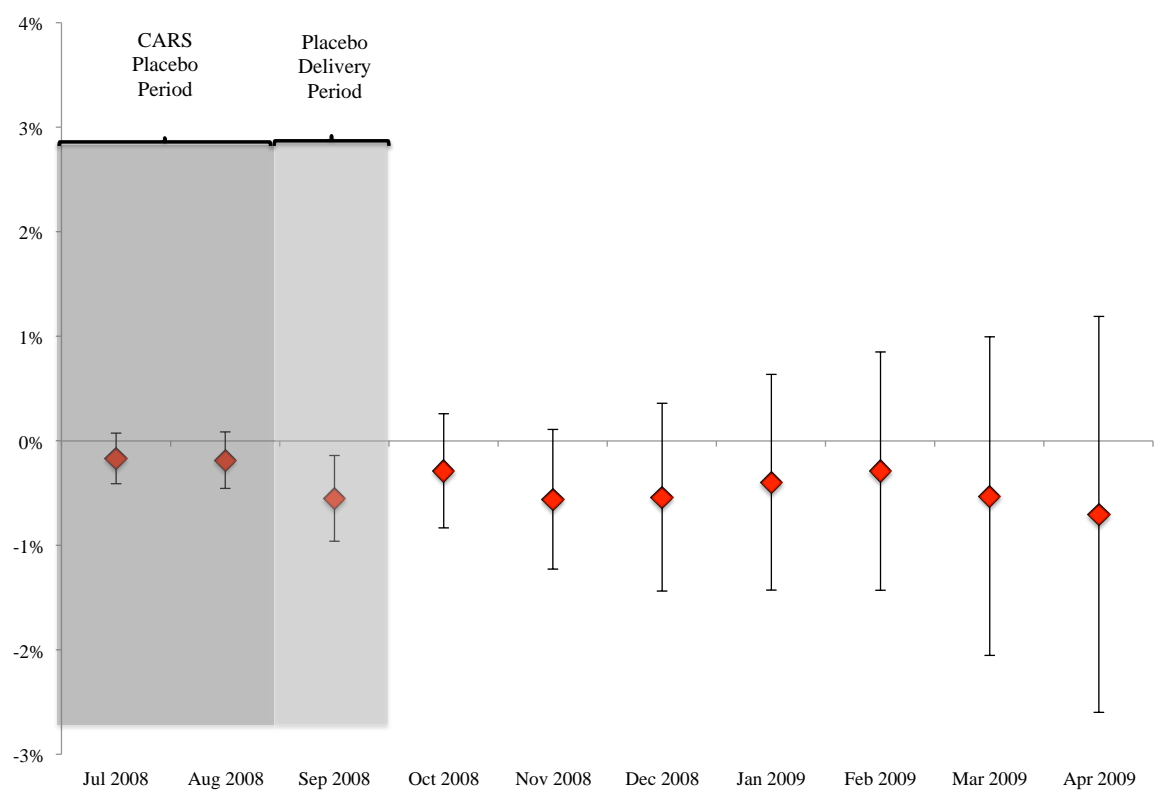

Figure 5: Placebo Test: Cumulative Change in Purchases during 2008. This figure plots the full set of Clunker coefficients and 95\% confidence intervals for the model reported in Table 7, Panel A. For each month between July 2008 and April 2009, the coefficient measures the cumulative difference (since July 2008) in the rate of new vehicle purchases associated with hypotheticallyeligible vehicles compared to similar ineligible vehicles. 
Table 1: CARS eligibility requirements and rebate amounts

\begin{tabular}{|c|c|c|c|c|}
\hline NEW VEHICle type & $\begin{array}{c}\text { NEW } \\
\text { VEHICLE } \\
\text { FUEL } \\
\text { ECONOMY }\end{array}$ & $\begin{array}{l}\text { TRADE-IN } \\
\text { VEHICLE } \\
\text { TYPE }\end{array}$ & $\begin{array}{c}\text { DIFFERENCE } \\
\text { IN MPG, } \\
\text { NEW VS. } \\
\text { TRADE-IN }\end{array}$ & $\begin{array}{l}\text { REBATE } \\
\text { AMOUNT }\end{array}$ \\
\hline \multirow[t]{2}{*}{$\begin{array}{l}\text { Passenger Automobile: } \\
\text { - All passenger cars. }\end{array}$} & \multirow[t]{2}{*}{$\begin{array}{c}\text { At least } 22 \\
\text { MPG }\end{array}$} & \multirow{2}{*}{$\begin{array}{l}\text { Passenger car, } \\
\text { Category } 1 \text { or } \\
2 \text { truck with } \\
\text { MPG } 18 \text { or } \\
\text { less }\end{array}$} & 4-9 MPG & $\$ 3,500$ \\
\hline & & & $\begin{array}{c}10 \mathrm{MPG} \text { or } \\
\text { more }\end{array}$ & $\$ 4,500$ \\
\hline \multirow{2}{*}{$\begin{array}{l}\text { Category } 1 \text { Truck: } \\
\text { - All SUVs w/GVWR }<=10,000 \text { lbs. } \\
\text { - Pickups w/GVWR }<8,500 \text { lbs. and } \\
\text { wheelbase }<=115 \text { in. } \\
\text { - Passenger vans and cargo vans w/GVWR } \\
<8,500 \text { lbs. and wheelbase }<=124 \text { in. }\end{array}$} & \multirow[t]{2}{*}{$\begin{array}{c}\text { At least } 18 \\
\text { MPG }\end{array}$} & \multirow[t]{2}{*}{$\begin{array}{l}\text { Passenger car, } \\
\text { Category } 1 \text { or } \\
2 \text { truck with } \\
\text { MPG } 18 \text { or } \\
\text { less }\end{array}$} & $2-5 \mathrm{MPG}$ & $\$ 3,500$ \\
\hline & & & $\begin{array}{l}5 \mathrm{MPG} \text { or } \\
\text { more }\end{array}$ & $\$ 4,500$ \\
\hline \multirow{3}{*}{$\begin{array}{l}\text { Category } 2 \text { Truck: } \\
\text { - Pickups w/GVWR }<=8,500 \text { lbs. and } \\
\text { wheelbase }>115 \text { in. } \\
\text { - Passenger vans and cargo vans w/GVWR } \\
<=8,500 \text { lbs. and wheelbase }>124 \text { in. }\end{array}$} & \multirow[t]{3}{*}{$\begin{array}{c}\text { At least } 15 \\
\text { MPG }\end{array}$} & \multirow[t]{2}{*}{$\begin{array}{c}\text { Category } 2 \\
\text { truck with } \\
\text { MPG } 18 \text { or } \\
\text { less }\end{array}$} & $1 \mathrm{MPG}$ & $\$ 3,500$ \\
\hline & & & $\begin{array}{c}2 \mathrm{MPG} \text { or } \\
\text { more }\end{array}$ & $\$ 4,500$ \\
\hline & & $\begin{array}{c}\text { Category } 3 \\
\text { truck }\end{array}$ & NA & $\$ 3,500$ \\
\hline $\begin{array}{l}\text { Category } 3 \text { Truck: } \\
\text { - Trucks w/GVWR 8,500-10,000 lbs. that } \\
\text { is either large cargo van or pickup trucks } \\
\text { w/cargo bed }>72 \text { in. }\end{array}$ & NA & $\begin{array}{c}\text { Category } 3 \\
\text { truck }\end{array}$ & $\begin{array}{l}\text { NA. New } \\
\text { vehicle must } \\
\text { be no larger } \\
\text { than } \\
\text { trade-in }\end{array}$ & $\$ 3,500$ \\
\hline
\end{tabular}

Source: National Highway Traffic Safety Administration (2009). Fuel economy requirements are based on EPA's combined city/highway ratings. To be eligible, a trade-in vehicle must have a fuel economy rating of 18 MPG or less. Category 3 trucks do not have EPA fuel economy ratings. 


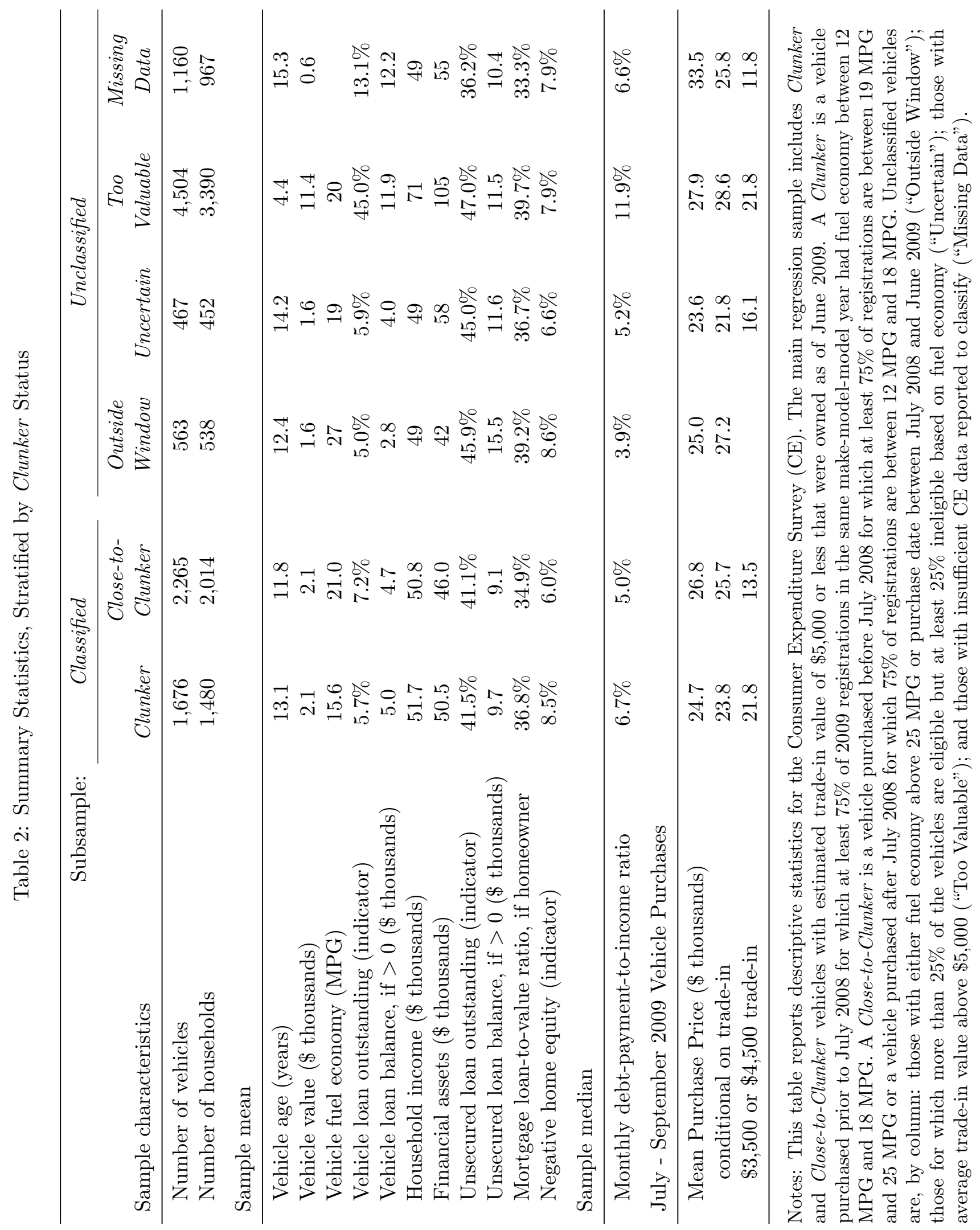


Table 3: The Impact of CARS on New Vehicle Purchases and Leases

Panel A: Cumulative rate of new vehicles purchased or leased since July 2009

\begin{tabular}{|c|c|c|c|c|}
\hline Estimated impact during CARS & $\begin{array}{c}\text { Sample } \\
\text { Size }\end{array}$ & $\begin{array}{c}\text { No } \\
\text { Controls }\end{array}$ & $\begin{array}{c}\text { All } \\
\text { Controls } \\
\text { Except MPG }\end{array}$ & $\begin{array}{c}\text { All } \\
\text { Controls }\end{array}$ \\
\hline Clunker (through Jul 2009) & 3,941 & $\begin{array}{c}0.36 \\
(0.20)\end{array}$ & $\begin{array}{c}0.37 \\
(0.20)\end{array}$ & $\begin{array}{c}0.54 \\
(0.32)\end{array}$ \\
\hline Clunker (through Aug 2009) & 3,548 & $\begin{array}{c}1.22 \\
(0.36)\end{array}$ & $\begin{array}{c}1.29 \\
(0.37)\end{array}$ & $\begin{array}{c}1.43 \\
(0.52)\end{array}$ \\
\hline Clunker (through Sep 2009) & 3,162 & $\begin{array}{c}1.43 \\
(0.43)\end{array}$ & $\begin{array}{c}1.56 \\
(0.45)\end{array}$ & $\begin{array}{c}1.72 \\
(0.63)\end{array}$ \\
\hline
\end{tabular}

Panel B: Cumulative expenditure on new vehicles purchased or leased since July 2009

\begin{tabular}{|c|c|c|c|c|}
\hline Estimated impact during $C A R S$ & $\begin{array}{c}\text { Sample } \\
\text { Size }\end{array}$ & $\begin{array}{c}\text { No } \\
\text { Controls }\end{array}$ & $\begin{array}{c}\text { All } \\
\text { Controls } \\
\text { Except MPG }\end{array}$ & $\begin{array}{c}\text { All } \\
\text { Controls }\end{array}$ \\
\hline Clunker (through Jul 2009) & 3,941 & $\begin{array}{c}64.1 \\
(43.0)\end{array}$ & $\begin{array}{c}69.9 \\
(43.4)\end{array}$ & $\begin{array}{c}99.9 \\
(71.4)\end{array}$ \\
\hline Clunker (through Aug 2009) & 3,548 & $\begin{array}{l}263.0 \\
(86.4)\end{array}$ & $\begin{array}{l}286.2 \\
(88.0)\end{array}$ & $\begin{array}{c}315.8 \\
(120.7)\end{array}$ \\
\hline Clunker (through Sep 2009) & 3,162 & $\begin{array}{c}326.5 \\
(106.9)\end{array}$ & $\begin{array}{c}368.0 \\
(111.3)\end{array}$ & $\begin{array}{c}403.7 \\
(151.2)\end{array}$ \\
\hline
\end{tabular}

Panel C: Implied unit purchase prices associated with CARS transactions

\begin{tabular}{ccccc} 
& Sample & No & All \\
Estimated impact during CARS & Size & $\begin{array}{c}\text { Controls } \\
\text { Concept MPG }\end{array}$ & $\begin{array}{c}\text { All } \\
\text { Controls }\end{array}$ \\
\cline { 2 - 5 } Clunker (through Jul 2009) & 3,941 & 17,784 & 19,024 & 18,470 \\
Clunker (through Aug 2009) & 3,548 & 21,523 & 22,161 & 22,146 \\
Clunker (through Sep 2009) & 3,162 & 22,912 & 23,632 & 23,475 \\
\hline
\end{tabular}

Notes: This table reports analysis of the rate and value of new vehicle purchases and leases during the CARS program and thereafter. The Clunker coefficients in Panel A are multiplied by 100 and measure the percentage point difference in cumulative vehicle purchases (since July 2009) associated with CARS-eligible trade-in vehicles compared to similar but ineligible trade-ins. Panel B reports specifications that measure the total dollar expenditure in the Clunkergroup. The regression sample includes Clunker and Close-to-Clunker vehicles, as defined in Table 2, with estimated trade-in value of $\$ 5,000$ or less that were owned as of June 2009. Panel C reports the vehicle purchase prices that took place because of CARS that are implied by the coefficient estimates in Panels A and B. The column headings indicate the control variables, which include vehicle age, trade-in value and fuel economy (MPG), household after-tax income, the number of $\mathrm{CE}$ interviews ever completed by the household, and the total number of CE interviews missed to date. Vehicle age is the the number of months since the January of the vehicle model-year. Vehicle trade-in value and fuel economy are averaged across drivetrain configurations of the make, model, and model-year. The standard errors, which are reported in parentheses, are calculated with observations clustered by household. 
Table 4: Trade-in Value and the CARS Program Response

Panel A: Baseline sample of vehicles with trade-in value less than or equal to $\$ 5,500$

\begin{tabular}{|c|c|c|c|c|}
\hline Dependent variable: & \multicolumn{2}{|c|}{$\begin{array}{l}\text { Cumulative purchases } \\
\text { and leases of new vehicles }\end{array}$} & \multicolumn{2}{|c|}{$\begin{array}{c}\text { Cumulative dollars } \\
\text { spent on new vehicles }\end{array}$} \\
\hline Sample period: & $\begin{array}{l}\text { Through } \\
\text { Aug } 2009\end{array}$ & $\begin{array}{l}\text { Through } \\
\text { Sep } 2009\end{array}$ & $\begin{array}{l}\text { Through } \\
\text { Aug } 2009\end{array}$ & $\begin{array}{l}\text { Through } \\
\text { Sep } 2009\end{array}$ \\
\hline Clunker & $\begin{array}{c}2.49 \% \\
(0.75)\end{array}$ & $\begin{array}{c}2.60 \% \\
(0.85)\end{array}$ & $\begin{array}{c}\$ 530.1 \\
(176.8)\end{array}$ & $\begin{array}{l}\$ 552.9 \\
(199.6)\end{array}$ \\
\hline Clunker $\times$ Value (in $\$$ thousands) & $\begin{array}{r}-0.53 \\
(0.21)\end{array}$ & $\begin{array}{c}-0.44 \\
(0.26)\end{array}$ & $\begin{array}{r}-106.0 \\
(47.5)\end{array}$ & $\begin{array}{r}-74.1 \\
(63.8)\end{array}$ \\
\hline Observations & 3,548 & 3,162 & 3,548 & 3,162 \\
\hline Clunker effect @ \$1500 Value & $\begin{array}{c}1.70 \\
(0.56)\end{array}$ & $\begin{array}{c}1.94 \\
(0.66)\end{array}$ & $\begin{array}{c}370.9 \\
(130.7)\end{array}$ & $\begin{array}{c}441.8 \\
(155.1)\end{array}$ \\
\hline
\end{tabular}

Panel B: Sample of vehicles with trade-in value less than or equal to $\$ 6,500$

\begin{tabular}{lcccc} 
Dependent variable: & \multicolumn{2}{c}{$\begin{array}{c}\text { Cumulative purchases } \\
\text { and leases of new vehicles }\end{array}$} & \multicolumn{2}{c}{$\begin{array}{c}\text { Cumulative dollars } \\
\text { spent on new vehicles }\end{array}$} \\
Sample period: & $\begin{array}{c}\text { Through } \\
\text { Aug 2009 }\end{array}$ & $\begin{array}{c}\text { Through } \\
\text { Sep 2009 }\end{array}$ & $\begin{array}{c}\text { Through } \\
\text { Aug 2009 }\end{array}$ & $\begin{array}{c}\text { Through } \\
\text { Sep 2009 }\end{array}$ \\
\cline { 2 - 5 } Clunker & 0.46 & 0.38 & 166.0 & 164.8 \\
& $(0.65)$ & $(0.77)$ & $(203.2)$ & $(234.8)$ \\
Clunker $\times($ Value $<\$ 1000)$ & 1.50 & 1.51 & 294.2 & 288.2 \\
Clunker $\times(<\$ 1000<$ Value $<\$ 2500)$ & $(0.82)$ & $(0.95)$ & $(235.6)$ & $(266.0)$ \\
Clunker $\times(<\$ 2500<$ Value $<\$ 5000)$ & 1.04 & 1.79 & 119.0 & 289.4 \\
& $(0.88)$ & $(1.10)$ & $(248.0)$ & $(306.7)$ \\
Observations & 0.48 & 1.06 & 70.0 & 217.4 \\
\hline
\end{tabular}

Notes: This table reports estimates from regressions of the number or value of new vehicle purchases on an indicator for CARS eligibility (Clunker) and its interaction with vehicle trade-in value. Panel A uses the same sample as Table 3 but includes an interaction with the vehicle's average trade-in value. Panel B uses an expanded sample - vehicles with trade-in value up to $\$ 6,500$ - and includes interactions of Clunker with indicators for various ranges of trade-in value. The excluded group is vehicles with trade-in value between $\$ 5,000$ and $\$ 6,500$. Each regression includes the full set of controls described in Table 3 . The standard errors, which are reported in parentheses, are calculated with observations clustered by household. 
Table 5: Household Liquidity and the CARS Program Response

\begin{tabular}{|c|c|c|c|c|c|}
\hline Dependent variable: & \multicolumn{5}{|c|}{$\begin{array}{c}\text { Number of new vehicles purchased or leased between } \\
\text { July and September } 2009\end{array}$} \\
\hline Clunker & $\begin{array}{c}2.33 \\
(0.78)\end{array}$ & $\begin{array}{c}2.18 \\
(0.84)\end{array}$ & $\begin{array}{c}3.42 \\
(1.08)\end{array}$ & $\begin{array}{c}2.91 \\
(1.13)\end{array}$ & $\begin{array}{c}3.37 \\
(1.67)\end{array}$ \\
\hline Clunker $\times$ Outstanding loan on vehicle & $\begin{array}{l}-2.80 \\
(1.07)\end{array}$ & & $\begin{array}{l}-2.30 \\
(1.05)\end{array}$ & & $\begin{array}{l}-2.15 \\
(1.28)\end{array}$ \\
\hline Clunker $\times$ Outstanding unsecured loan & & $\begin{array}{l}-0.07 \\
(1.04)\end{array}$ & & & \\
\hline $\begin{array}{l}\text { Clunker } \times \text { Assets bottom tercile } \\
(<\$ 300) \\
\text { Clunker } \times \text { Assets middle tercile (omitted) } \\
(\$ 300-\$ 4,500)\end{array}$ & & & & $\begin{array}{l}-1.65 \\
(1.07)\end{array}$ & $\begin{array}{l}-1.23 \\
(1.19)\end{array}$ \\
\hline $\begin{array}{l}\text { Clunker } \times \text { Assets upper tercile } \\
(>\$ 4,500)\end{array}$ & & & & $\begin{array}{l}-0.69 \\
(1.42)\end{array}$ & $\begin{array}{l}-0.78 \\
(1.61)\end{array}$ \\
\hline Clunker $\times$ Income & & & $\begin{array}{l}-0.01 \\
(0.01)\end{array}$ & & $\begin{array}{c}0.02 \\
(0.02)\end{array}$ \\
\hline Clunker $\times$ Value & & & $\begin{array}{l}-0.42 \\
(0.30)\end{array}$ & & $\begin{array}{l}-0.48 \\
(0.32)\end{array}$ \\
\hline Observations & 2,673 & 2,722 & 2,673 & 2,106 & 1,821 \\
\hline
\end{tabular}

Notes: This table reports estimates from regressions of the number of new vehicle purchases on an indicator for CARS program-eligibility (Clunker) and its interaction with household financial variables. These variables include indicators for whether the potential trade-in is encumbered by an outstanding loan, whether the household has an outstanding unsecured loan, the tercile of the household's liquid assets, and the household's after-tax income. The model includes a control for each financial variable when it is interacted with Clunker. Coefficients are multiplied by 100 to reflect purchase rates in percentage points. The model also includes the full set of control variables used in Table 3. Assets are measured as the sum of reported checking and savings account balances. The regression sample is the same as in Table 3, subject to the further requirement that the financial variables included in the specification are non-missing in the CE. The standard errors, which are reported in parentheses, are calculated with observations clustered by household. 
Table 6: Household Debt Capacity and CARS Program Response

Dependent variable:

Clunker

Clunker $\times$ Income bottom tercile $(<\$ 24,000)$

Clunker $\times$ Income middle tercile (omitted) $(\$ 24,000-\$ 57,500)$

Clunker $\times$ Income upper tercile $(>\$ 57,500)$

Clunker $\times($ PTI already $>1 / 3)$

Clunker $\times(\mathrm{PTI}>1 / 3$ with $\$ 0<$ payment $<\$ 500)$

Clunker $\times(\mathrm{PTI}>1 / 3$ only with payment $>\$ 500)$

Clunker $\times$ Mortgage LTV bottom tercile $(\mathrm{LTV}=0)$

Clunker $\times$ Mortgage LTV middle tercile (omitted) $(0<\mathrm{LTV}<0.5)$

Clunker $\times$ Mortgage LTV upper tercile $(\mathrm{LTV}>0.5)$

Clunker $\times$ Negative home equity (indicator)

Number of new vehicles purchase or leased between July and September 2009

$\begin{array}{llll}1.97 & 1.32 & 1.23 & 2.12\end{array}$

$-0.21$

1.04

$-0.47$

\begin{tabular}{lllll} 
Observations & 3,162 & 2,722 & 2,010 & 2,010 \\
\hline
\end{tabular}

Notes: This table reports estimates from regressions of the number of new vehicle purchases on an indicator for CARS program-eligibility (Clunker) and its interaction with household financial variables. These variables include indicators for ranges of household income, debt-payment-to income ratio, mortgage loan-to value ratio, and an indicator for negative home equity. The model includes a control for each financial variable when it is interacted with Clunker. Coefficients are multiplied by 100 to reflect purchase rates in percentage points. The model also includes the full set of control variables used in Table 3. The payment-to-income ratio (PTI) indicators consider whether a household's PTI would be above $1 / 3$ after including a hypothetical new debt payment of various sizes. The regression sample is the same as in Table 3 , subject to the further requirement that the financial variables included in the specification are non-missing in the CE. The standard errors, which are reported in parentheses, are calculated with observations clustered by household. 
Table 7: Placebo Tests of CARS Program Response

Panel A: Analysis of Placebo Period, 2008

Dependent Variable:

Number of new vehicles purchased or leased between July and September 2008

\begin{tabular}{|c|c|c|c|}
\hline Clunker & $\begin{array}{l}-0.36 \\
(0.36)\end{array}$ & $\begin{array}{l}-0.18 \\
(0.45)\end{array}$ & $\begin{array}{l}-0.03 \\
(0.53)\end{array}$ \\
\hline Clunker $\times$ Value & & $\begin{array}{l}-0.09 \\
(0.19)\end{array}$ & $\begin{array}{l}-0.02 \\
(0.21)\end{array}$ \\
\hline Clunker $\times$ Outstanding loan on vehicle & & & $\begin{array}{l}-0.31 \\
(0.31)\end{array}$ \\
\hline Clunker $\times$ Income & & & $\begin{array}{c}0.00 \\
(0.00)\end{array}$ \\
\hline Observations & 3,003 & 3,003 & 2,500 \\
\hline $\begin{array}{l}\text { Panel B: Analysis of Pla } \\
\text { Dependent Variable: }\end{array}$ & \multicolumn{3}{|c|}{$\begin{array}{l}\text { Number of used vehicles purchased } \\
\text { between July and September } 2009\end{array}$} \\
\hline Clunker & $\begin{array}{c}0.58 \\
(0.52)\end{array}$ & $\begin{array}{c}0.66 \\
(0.83)\end{array}$ & $\begin{array}{c}1.40 \\
(0.99)\end{array}$ \\
\hline Clunker $\times$ Value & & $\begin{array}{l}-0.04 \\
(0.26)\end{array}$ & $\begin{array}{l}-0.06 \\
(0.30)\end{array}$ \\
\hline Clunker $\times$ Outstanding loan on vehicle & & & $\begin{array}{l}1.05 \\
(1.64)\end{array}$ \\
\hline Clunker $\times$ Income & & & $\begin{array}{l}-0.01 \\
(0.01)\end{array}$ \\
\hline Observations & 3,162 & 3,162 & 2,673 \\
\hline
\end{tabular}

Notes: This table reports regression estimates from two placebo tests. Panel A reports analysis of CARS as if it had run in July and August of 2008. Following an identical procedure to our main analysis, we classify vehicles owned as of June 2008 according to their hypothetical eligibility for CARS and estimate the cumulative new vehicle purchases or leases associated with eligible vehicles compared to ineligible vehicles. Panel B reports analysis of used vehicle purchases, which were not eligible for the CARS rebate. Repeating the main analysis of Table 3 Panel A, we estimate the impact of CARS on used vehicle purchases. Coefficients are multiplied by 100 to reflect purchase rates in percentage points. Each model includes the full set of control variables listed in Table 3. The standard errors, which are reported in parentheses, are calculated with observations clustered by household. 


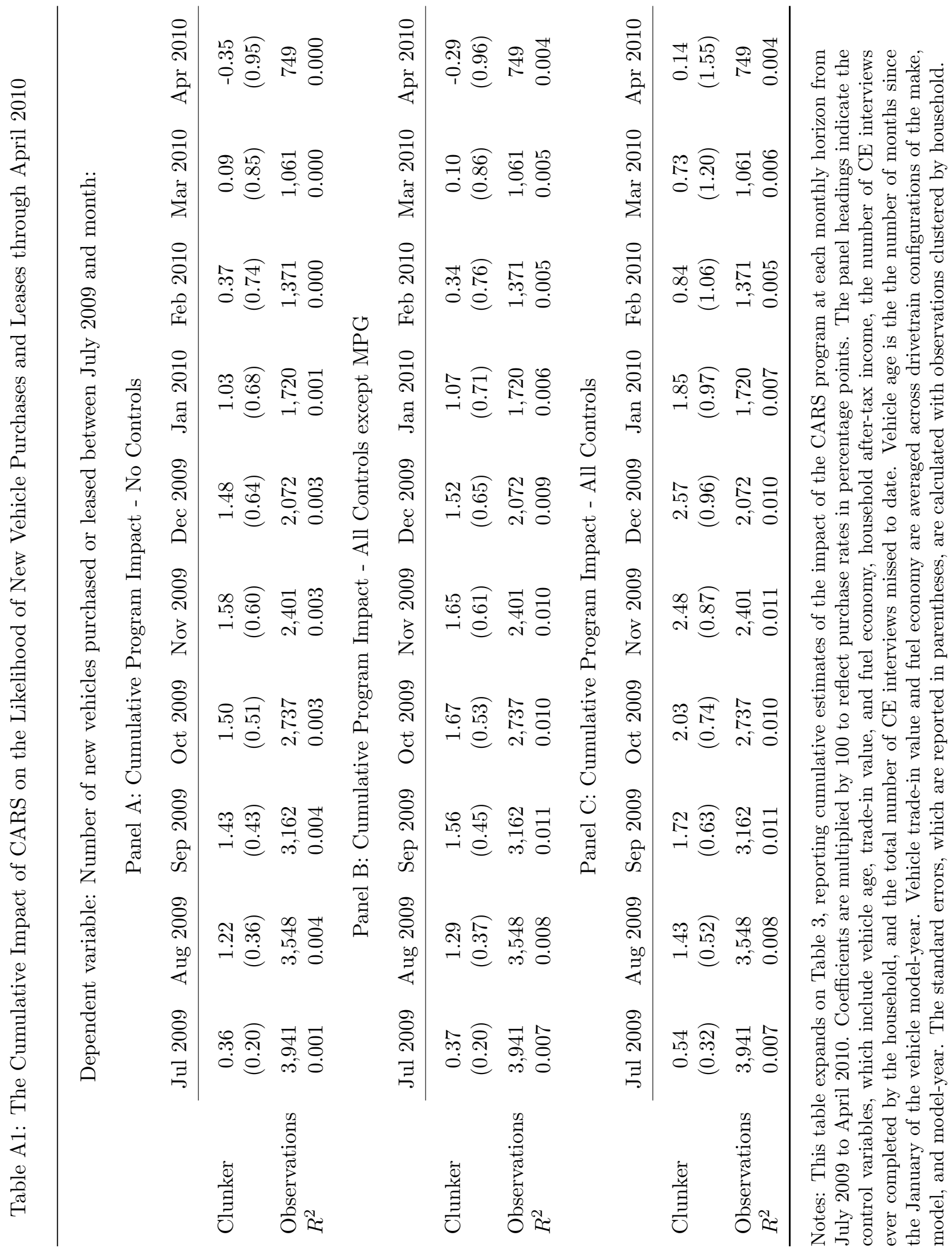




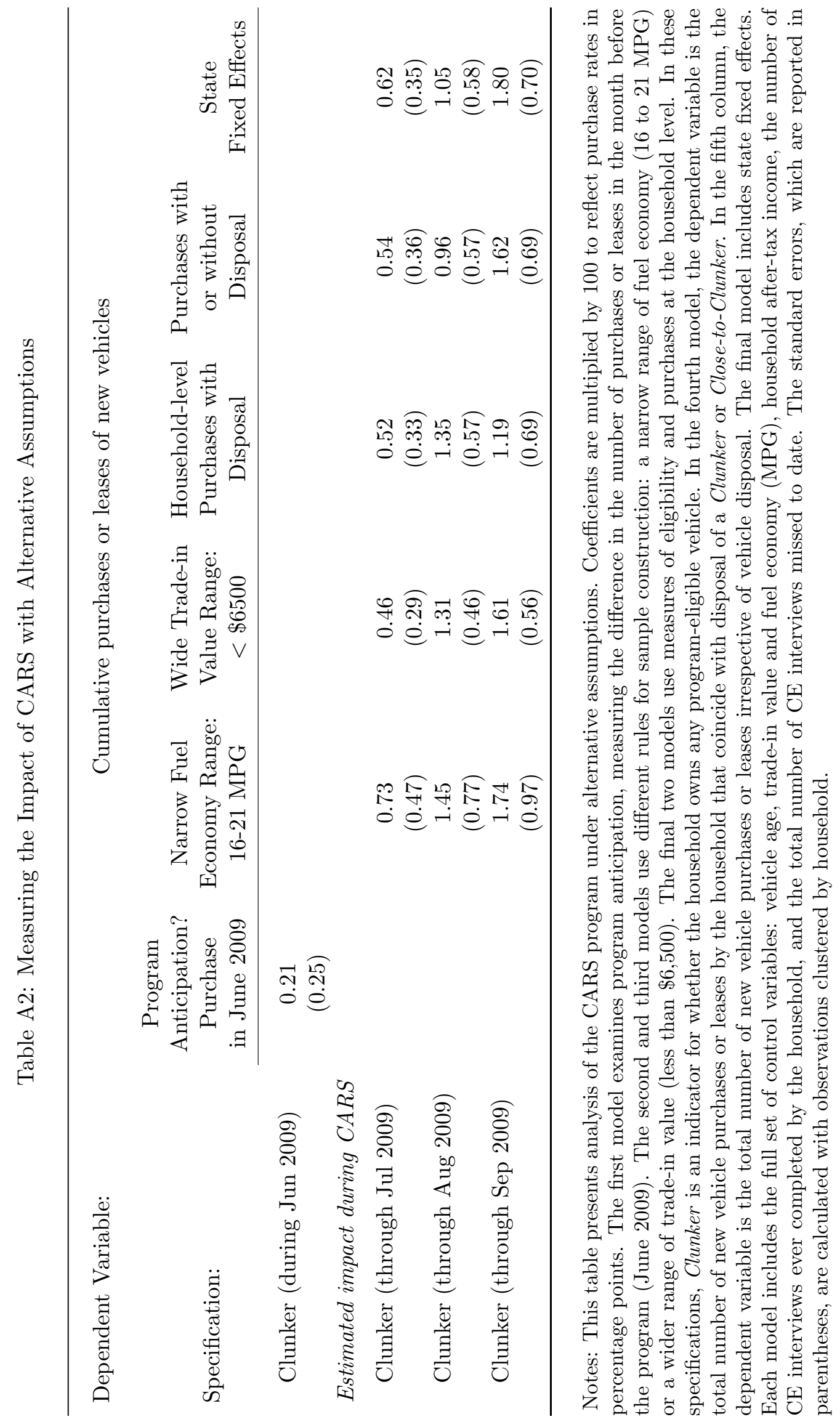


Table A3: Household Liquidity and CARS Program Response, Controlling for Debt Capacity

Dependent variable:

Clunker

Clunker $\times$ Outstanding loan on vehicle

Clunker $\times$ Income bottom tercile $(<\$ 24,000)$

Clunker $\times$ Income middle tercile (omitted) $(\$ 24,000-\$ 57,500)$

Clunker $\times$ Income upper tercile $(>\$ 57,500)$

Clunker $\times($ PTI already $>1 / 3)$

Clunker $\times(\mathrm{PTI}>1 / 3$ with $\$ 0<$ payment $<\$ 500)$

Clunker $\times(\mathrm{PTI}>1 / 3$ only with payment $>\$ 500)$

Clunker $\times$ Mortgage LTV bottom tercile $(\mathrm{LTV}=0)$

Clunker $\times$ Mortgage LTV middle tercile (omitted) $(0<\mathrm{LTV}<0.5)$

Clunker $\times$ Mortgage LTV upper tercile $(\mathrm{LTV}>0.5)$

Clunker $\times$ Negative home equity (indicator)
Number of new vehicles purchased or leased between July and September 2009

$\begin{array}{cccc}2.81 & 1.50 & 1.27 & 2.15 \\ (1.06) & (0.84) & (1.37) & (1.02) \\ -2.93 & -2.76 & -1.65 & -1.64 \\ (1.12) & (1.07) & (0.77) & (0.63)\end{array}$

$-0.48$

1.00

$-0.35$

\begin{tabular}{lllll} 
Observations & 2,673 & 2,673 & 1,983 & 1,983 \\
\hline
\end{tabular}

Notes: This table repeats the analysis of Table 5 but with additional controls for Clunker interacted with household debt capacity. Coefficients are multiplied by 100 to reflect purchase rates in percentage points. The standard errors, which are reported in parentheses, are calculated with observations clustered by household. 